\title{
The State of Play
}

$\oplus$ 


\title{
Troo Conceptions of Mind and Action
}

\author{
KNOWING HOW AND THE PHILOSOPHICAL THEORY \\ OF INTELLIGENCE
}

\author{
John Bengson and Marc A. Moffett
}

Perhaps it is a pity that the Theory of Knowledge and the Theory of Conduct have fallen into separate compartments. (It certainly was not so in Socrates' time, as his interest in the relation between eidos and technê bears witness.) If we studied them together, perhaps we might have a better understanding of both.

H. H. PRICE, Thinking and Representation

SINCE GILBERT RYLE'S attack on what he unsympathetically labeled the "intellectualist legend," it has been widely accepted that knowledge how to do things is fundamentally distinct from knowledge that something is the case. ${ }^{1}$ In recent years, however, this orthodox anti-intellectualist position has come under increasing pressure. At issue in the debate is not simply knowledge how, but altogether different conceptions of the mind and its relation to action.

The present book contains fifteen essays (including this one) that engage various issues in this broader debate, probing the intersection of knowledge, mind, and action. Some of our actions manifest states or qualities of mind, such as intelligence and skill. But what are these states and qualities, and how are they manifested in action? In this chapter, we examine the state of play in the current debate on knowledge how and begin to articulate and evaluate general intellectualist and anti-intellectualist answers to such questions. Inter alia, we attempt to situate

I. It has been suggested that a fundamental distinction between knowledge how to act (hereafter, simply 'knowledge how') and knowledge that something is the case (hereafter, simply 'knowledge that') is also found, prior to Ryle, in the work of Dewey (1922), Heidegger (1926), and Piaget (1937) and even earlier in such thinkers as Plato and Aristotle. We will not pursue this suggestion here. 
recent discussion of knowledge how in a much larger debate about the nature of intelligence and intelligent action. ${ }^{2}$

Our primary aim is to explore the opposing intellectualist and antiintellectualist views originating in Ryle's discussion (\$I $)$, investigating some of the issues and questions that motivate and sustain the conflict between them $(\$ \$ 2-3)$. Another aim is to indicate how, and to what extent, an adequate account of knowledge how is not a peripheral philosophical goal. The reason is not simply that such an account may hold the key to integrating the theory of knowledge and the theory of conduct, perhaps leading to a better understanding of both (as Price observed). The current theoretical milieu is one which makes the debate about knowledge how more pressing than at any time since Ryle. Many of the most influential thinkers working in such disparate areas as epistemology, philosophy of action, ethics, philosophy of language, linguistics, theory of education, cognitive ethology, psychology, philosophy of mind, phenomenology, and cognitive science seem to have found the notion of knowledge how central to their theoretical projects $\left(\$_{4}\right)$. As we shall see, this is not accidental: knowledge how may serve as a hinge on which our general understanding of mind and action turns.

\section{Ryle and the Philosophical Theory of Intelligence}

Contemporary debates over the nature of knowledge how owe much to Ryle's treatment in his 1945 lecture "Knowing How and Knowing That" and the second chapter of his 1949 monograph The Concept of Mind. The aim of this section is to introduce some of the main contours of the dialectic between two very different philosophical perspectives suggested by Ryle's discussion, in which intellectualist and anti-intellectualist views of knowledge how emerge as specific instances of far more general theses about intelligence and intelligent action broadly understood. The plan is to highlight several interrelated questions that seem to have fueled Ryle's own general anti-intellectualism but have been largely neglected or backgrounded in recent discussion of knowledge how.

\footnotetext{
2. Notably, Stanley and Williamson (200I, 444) gesture at this larger debate when, at the close of their recent defense of intellectualism in the specific case of knowledge how, they write: "Neglect of this fact [that knowledge how is a species of knowledge that] impoverishes our understanding of human action, by obscuring the way in which it is informed by intelligence." In his critical response, Noë $(2005,278)$ likewise gestures at the idea that intellectualism and anti-intellectualism are not simply views about knowledge how, but conflicting accounts of "our mental nature." We believe that these suggestive remarks invite further exploration; hence the present chapter.
} 


\section{I.I Intellectualism}

In chapter 2 of The Concept of Mind, Ryle sets out

to show that there are many activities which directly display qualities of mind, yet are neither themselves intellectual operations nor yet effects of intellectual operations. (1949, 26)

The "many activities" to which Ryle is referring are basically those activities we know how to do. However, as he makes clear, Ryle's initial starting point is not knowing how in particular, but rather what he refers to as states (acts, processes, etc.) of "intellect and character" more generally. Such states of agents are designated by "intelligence-epithets" such as 'intelligent,' 'clever,' 'sensible,' 'skillful,' 'canny,' 'wise,' 'prudent,' 'careful,' 'rational,' 'stupid,' 'silly,' and 'idiotic' (see, e.g., 1949, 25, 27, 46, and 280; 1945, I, 3, 5, and 10); correlatively, "qualities of intellect and character" (1949, 7, 6I, and esp. I26 and I35), which are properties of actions, are designated by the corresponding adjectival and adverbial intelligence-epithets such as 'intelligently,' 'cleverly', and the like. ${ }^{3}$

Interestingly, at various points Ryle uses 'intelligence' in a broad sense that includes all members of this group, including stupidity and idiocy. ${ }^{4}$ Hereafter, we reserve 'intelligence' (lowercase 'i') for intelligence in the narrow sense, namely, that which is intelligent but not stupid, idiotic, and so forth; we will use 'Intelligence' (capital 'I') as an umbrella term covering all states of intellect

3. Although Ryle is not always clear about this distinction, intelligence-epithets can, with equal felicity, designate states of agents (as when we say that an individual is clever) or properties/ qualities of actions performed by those agents (as when we say that an individual acted cleverly). The latter may be possessed by action types (e.g., choosing to eat healthy foods is sensible), as well as particular actions by particular individuals; we focus on the latter. The relation between the relevant states of agents and qualities of actions is detailed in note 5. The relation between intelligence-epithets and various other evaluative epithets (e.g., 'correctly', 'validly') is discussed in note 28 .

4. Thus Ryle (1945, I) speaks of "the several concepts of intelligence," by which is meant "the more determinate" members of the family of "mental-conduct concepts" expressed by terms such as those listed in the text $(1949,25)$. This family is a proper subset of mental phenomena (cf. sensations and emotions; see, e.g., 1949, 135 and 204). It does not, prior to theorizing, include propositional or factual attitudes and abilities or dispositions; rather, as we shall see, such attitudes and abilities or dispositions serve as candidate grounds or bases-intellectual and non-intellectual grounds or bases (analysans, explanans, explicans, etc.), respectivelyfor the indicated states and qualities. Snowdon (chapter 2) articulates several worries about Ryle's efforts to theorize about this family, a few of which intersect with the present treatment. 
and character, including intelligence (in the narrow sense), stupidity, and idiocy.'

Such terminology enables us to respect the complex relations between various states of Intelligence. Particular states of Intelligence obviously come apart, and not simply because some have a positive valence (e.g., intelligence) whereas others have a negative valence (e.g., stupidity): for instance, one might play chess intelligently but not cleverly or one might know how to prune trees (Ryle's example) but not yet be skilled at pruning trees (i.e., prune trees skillfully). Of course, it does not follow that the various states of Intelligence are completely dissimilar. Indeed, a philosophical theory of Intelligence-Ryle's concern-aspires to provide an account, not of this or that particular state of intellect and character, but of what all of them have in common, that is, of Intelligence generally.

Intelligence-epithets often modify overt behaviors, such as pruning trees. But Ryle is keenly aware that Intelligent actions, such as pruning trees skillfully, are not distinguishable from non-Intelligent actions in virtue of any overt features of the performance; rather, we must "look beyond the performance itself" (1949, 45; cf. 25, 32-33, and 40-4I). On what basis, then, are we to draw the distinction between the Intelligent and the non-Intelligent? Call this the delineation question, which can be formulated generally, as follows:

\section{The Delineation Question}

What makes the difference between behaviors that do, and overtly indistinguishable behaviors that do not, display states of Intelligence?

It is here that an intellectualist conception of mind and action, which privileges the intellect ("intellectual operations") by "defin[ing I] ntelligence in terms of the apprehension of truths" (1949, 27), arises. More generally, Ryle tells us, intellectualism holds:

(I) that Intelligence [involves] those specific internal acts which are called acts of thinking, namely, the operations of considering propositions; (2) that practical activities merit their titles 'intelligent,' 'clever', and the rest only because they are accompanied by some such internal acts of

5. It is natural to think that ordinary thought and language vindicate Ryle's use of a broad sense of 'intelligent.' Correlatively, a broad sense of 'stupid' that designates a lack of all states of intellect and character-the absence of Intelligence-seems to be operative in an assertion such as "It's just a stupid machine; it can't think." As we shall use the term, $\delta$ is Intelligent if and only if $\delta$ is or exercises or displays a state of Intelligence. A particular behavior or action $\varphi$ (e.g., pruning trees) by a particular individual $x$ displays a state of Intelligence (e.g., the action displays skill) if and only if $x$ exercises a state of Intelligence in $\varphi$-ing (e.g., $x$ exercises skill in pruning trees); in such a case, $\varphi$ is an exercise of a state of Intelligence (e.g., $\varphi$ is an exercise of skill), and $\varphi$ has a quality of Intelligence (e.g., $\varphi$ is skillful or done skillfully). 
considering propositions (and particularly "regulative" propositions). (Ryle 1945, I; cf. 1949, 26ff. and I37)

Internal, nonovert mental states of grasping propositions thus are said to make the difference between the Intelligent and the non-Intelligent.

As suggested by this quotation from Ryle, intellectualism can be understood as the conjunction of two theses, the first of which concerns the aforementioned states of Intelligence and the second of which concerns the relation between these states and action (the exercise of Intelligence):

$\left[\mathrm{I}_{\mathrm{MIND}}\right]$ A state $\sigma$ is a state of Intelligence if and only if $\sigma$ is or involves ${ }^{6}$ a certain type of internal state of engaging propositional content.

$\left[\mathrm{I}_{\mathrm{ACTION}}\right]$ An individual $x$ exercises a state of Intelligence in performing an action $\varphi$ (i.e., $x \varphi$-s Intelligently) if and only if $x \varphi$-s and $x$ has some state $\sigma$ such that (i) $\sigma$ is or involves a certain type of internal state of engaging propositional content and (ii) $\sigma$ is appropriately causally (or otherwise explanatorily ${ }^{7}$ ) related to the production of $\varphi$.

Where the broad category picked out by the expression 'internal state of engaging propositional content' includes such intellectual phenomena as having a propositional attitude (a way of "latching onto" propositional content) and reasoning (a way of "manipulating" propositional content), as well as other conceptual attitudes. ${ }^{8}$ We will often focus on propositional attitudes.

6. We state the theses here and below as specifying what the phenomenon designated by the left-hand side is or involves. The relevant relation of being or involving is distinct from mere equivalence, which cannot sustain the claim of asymmetric determination, dependence, or priority that seems to be essential to the views in question (for discussion of such a stronger, asymmetric relation, see, e.g., Kim 1974, 1994; Fine 1995; Correia 2005, chs. 3-4; and Schaffer 2009a). Specifically, the theses should be interpreted as saying that the phenomenon designated by the left-hand side is at least partially grounded in-and in this sense is or involves' - the phenomenon designated by the right-hand side (i.e., the former holds at least partly in virtue of the latter). They may but need not specify, say, identities or analyses, for reasons of the sort discussed in note II.

7. Some intellectualists may wish to understand the relation in terms of, say, noncausal rationalizing explanation or functional (or teleological) explanation. We will leave this qualification implicit in what follows.

8. While Ryle sometimes focuses on acts of thinking and theorizing, and on knowledge, grasp, or apprehension of truths or facts, as well as acts of considering, it is clear that the relevant category-intellectual operations - includes most, if not all, nonaffective, nonsensory states that go by the name of propositional attitudes or factual attitudes (see Vendler 1967) in contemporary philosophical parlance (e.g., acknowledging that p, recognizing that p, judging that $\mathrm{p}$, accepting that $\mathrm{p}$, believing that $\mathrm{p}$, perceiving that $\mathrm{p}$, knowing that $\mathrm{p}$, and so forth). The 
These intellectualist theses need not be motivated solely by their status as responses to the delineation question. It is difficult to deny that at least some Intelligent actions are preceded by internal states of engaging propositional content. To take a simple example, many of us still recite "Righty, tighty; lefty, loosey" before unscrewing a bolt. In such a case, we are explicitly considering the regulative proposition on which we subsequently act. To the extent that the Intelligence of the action is not a brute and inexplicable fact but is somehow linked to the presence of such prior considering, such considering (regardless of whether it is conscious or explicit) $)^{9}$ can be said in general to be what confers Intelligence on subsequent action. Such considering-and states relevantly like it—can in turn be said to have the profile Producer of Intelligence. Consequently, intellectualism, which posits just this profile, may be regarded as enjoying prima facie motivation: to wit, Intelligent actions are just those actions that are preceded by internal states of engaging propositional content (e.g., considering a regulative proposition).

Although $\left[\mathrm{I}_{\mathrm{MIND}}\right]$ and $\left[\mathrm{I}_{\mathrm{ACTION}}\right]$ are quite general, they have a variety of specific applications. One important application concerns knowledge how to act, a state of Intelligence to which Ryle devotes much attention (see, e.g., 1945, $7 \mathrm{ff}$. and I949, 28ff.). Intellectualism entails, by [ $\left.\mathrm{I}_{\mathrm{MIND}}\right]$, that knowledge how is a matter of possessing some relevant propositional attitude (or combination of propositional attitudes) and, by $\left[\mathrm{I}_{\mathrm{ACTION}}\right]$, that actions which display knowledge how are always produced by a causal process somehow involving the relevant propositional attitude (or combination of propositional attitudes)..$^{10}$ More precisely:

$\left[\mathrm{I}_{\text {KNOw-HOw }}\right]$ A state $\sigma$ of an individual $x$ is a state of knowing how to $\varphi$ if and only if $\sigma$ is or involves $x$ 's having some relevant propositional attitude(s) regarding $\varphi$-ing. ${ }^{\prime \prime}$

relevant states are "internal" in at least the sense that they are not overt; however, intellectualism is wholly compatible with anti-individualism (Burge 1979) and various other externalist theses.

9. Ryle acknowledges that intellectual operations may be "implicit" (1945, 7) and that their exercise may be "very swift and go quite unmarked by the agent" (1949, 29). Cf. Fodor (1968) and Dennett (1982) on some varieties of implicit (tacit, etc.) representation.

Io. 'Relevant' signifies a restriction to a specific type of propositional attitude(s). Such a restriction would be required to avoid rendering each and every state of Intelligence equivalent to knowledge how. All the same, the restriction is not obligatory; the significance of this option is discussed in note 27 .

II. Ryle allows that proponents of intellectualism might "reduce" knowledge how to knowledgethat (or a "set" or "sandwich" of "knowings-that"; 1945, Io and I5), but it is also open to them to find some other propositional attitude (recall note 8) and to treat "know-that... as the 
$\left[\mathrm{I}_{\text {KH-ACTION }}\right] x$ exercises knowledge how to $\varphi$ in performing an action $\varphi$ if and only if $x \varphi$-s and $x$ has some state $\sigma$ such that (i) $\sigma$ is or involves some relevant propositional attitude(s) regarding $\varphi$-ing and (ii) $\sigma$ is appropriately causally related to the production of $x$ 's $\varphi$-ing.

Analogous theses apply to other phenomena answering to mental-conduct concepts, including those expressed by terms such as 'intelligence' and 'skill.' Intellectualism entails that the grounds of knowledge how, intelligence, and skill are propositional, and exercises thereof are propositionally guided, through and through. ${ }^{12}$

\section{I.2 Four Arguments against Intellectualism}

Ryle is no friend to intellectualism. He takes it to be the "prevailing doctrine" (1945, I, 2, and 3) and one of the "main supports" for the pernicious "paramechanical myth" of "occult Forces" or internal mental causes (1949, 27; cf.

ideal model of all [I]ntelligence" (1945, 5 emphasis added). Nor must the proponent of intellectualism view the relation between knowledge how and intellectual states as strict identity or reduction; a nonreductive approach may be allowed. For example, Ryle-who seems to have used the term 'reduce' broadly to include, e.g., identification as well as grounding-suggests that his opponent may treat knowledge how as "derived from" (1949, 3I) propositional attitudes. To summarize: the core contention of intellectualism seems to be that knowledge how and other states of Intelligence are at least partially grounded in intellectual states such as propositional attitudes (see also \$2.I). While it might be suggested that this characterization of intellectualism is too broad, it bears emphasizing that, as we shall see, Ryle's basic objections in his 1945 lecture and The Concept of Mind apply equally to intellectualism so characterized, and he undoubtedly would have rejected this broad intellectualism as vociferously as a narrower, more reductionistic intellectualism.

I2. As indicated in note Io, different states of Intelligence (intelligence, skill, cleverness, stupidity, idiocy, etc.) could be said to require different types of attitude or combination thereof (e.g., believing, accepting, contemplating, choosing, seeming, intending, neglecting, knowing) or different types of proposition or combination thereof (e.g., that step B follows step A, that this is a way of $\varphi$-ing, that $\varphi$-ing is best done by $\psi$-ing, that it is rationally required to $\varphi$ when C). Although determining which attitude(s) or proposition(s) are required for different states of Intelligence may require empirical investigation, it is plausible to think, as Ryle does, that whether any such attitudes or propositions are required at all for a given state to be properly understood as an instance of Intelligence (rather than not) is a philosophical question. (Compare the a posteriori functionalist thesis that, roughly, mental states are functional states, although which mental state is which functional state is a partly empirical question.)

A note on skill: It is important to recognize that intellectualists distinguish sharply between skills and abilities or dispositions. Skill is a state of Intelligence, whereas mere ability or disposition is not (recall note 4 ); consequently, according to intellectualism, skills but not abilities or dispositions must be at least partially grounded in propositional attitudes. This approach might be motivated by the idea that all skills (but not all abilities or dispositions) require at least some Intelligence, which in turn involves knowledge that partly underwrites the skilled agent's power to act as she does, namely, skillfully. We return to the issue of skill later. 
I8-24). ${ }^{13} \mathrm{He}$ maintains that it entails a severely mistaken view of education as the mere imparting of truths (1945, 15-16) and, more generally, serves to misrepresent "daily experience" and the "quite familiar" facts of "ordinary life" (e.g., 1949, 32; 1945, 6; 1949, 28). Although Ryle suggests that he "relies on variations of one argument" to make his case against intellectualism $(1945,2)$, his critical discussion actually mentions several distinct types of argument, centering on four. Each of these four types of argument can be seen as focused on an ordinary question that Ryle takes intellectualism to be unable to answer satisfactorily. We consider each in turn, beginning with Ryle’' (1940, 38; 1945; 1949, ch. 2) much discussed regress argument.

Let $\alpha$ be some action that is an exercise of a state of Intelligence (e.g., an exercise of knowledge how). By $\left[\mathrm{I}_{\mathrm{ACTION}}\right]$ (or $\left[\mathrm{I}_{\text {KH-ACTION }}\right]$ ), $\alpha$ requires a distinct internal state $\alpha^{*}$ of engaging propositional content that is causally related to the production of (in short, 'produces') $\alpha$. But, according to Ryle, a state of engaging propositional content is itself something that can be exercised either Intelligently or not, and, Ryle implies, if it is not (e.g., if one does not consider a proposition Intelligently), then its product, $\alpha$, cannot be Intelligent (or an exercise of knowledge how) - which ex bypothes $i$ it is. So the exercise of $\alpha^{*}$ must be an exercise of a state of Intelligence (or the exercise of $\alpha^{*}$ must exercise knowledge how): that is, $\alpha^{*}$ must be Intelligently exercised. ${ }^{14}$ But then, by $\left[\mathrm{I}_{\mathrm{ACTION}}\right]$ (or $\left[\mathrm{I}_{\text {KH-ACTION }}\right]$ ), it follows that the Intelligent exercise of $\alpha^{*}$ also requires a distinct internal state $\alpha^{* *}$ of engaging propositional content that produces $\alpha^{*}$. Since the same reasoning applies to $\alpha^{* *}$ (whose Intelligent exercise will require $\alpha^{* * *}$, and so on ad infinitum), a regress ensues.

Of course, this is simply one way to implement or interpret the core idea behind Ryle's regress argument. That core idea appears to be that intellectualists fail to provide a satisfactory, non-regress-inducing answer to the question of what it is for intellectual states themselves to be exercises of states of Intelligence. Ryle summarizes:

\footnotetext{
13. While Ryle's stated target is usually Plato or Descartes, whose doctrines of a tripartite soul and a mind-body dualism (respectively) Ryle vehemently opposed, it is worth noting that an intellectualist perspective was also espoused, albeit in perhaps less blatant forms, by several of Ryle's more immediate influences, including the Oxonian Cook Wilson (see, e.g., 1926, \$I2), the Phenomenologist Edmund Husserl (see, e.g., 1901/1913), and Gottlob Frege (see, e.g., 1918/1956,310).

14. Ryle (1949, 31; cf. ro): "According to the [intellectualist] legend, whenever an agent does anything intelligently, his act is preceded and steered by another internal act of considering a regulative proposition appropriate to his practical problem. But what makes him consider the one maxim which is appropriate rather than any of the thousands which are not? Why does the hero not find himself calling to mind a cooking-recipe, or a rule of Formal Logic? Perhaps he does, but then his intellectual process is silly and not sensible." See also Ryle (1940, 39). We return to these issues in $\$ \$ 2.2-4$, where we discuss how intellectualists might attempt to resist the idea that an act must itself exercise Intelligence in order to produce an Intelligent action.
} 
They postulate an internal shadow-performance to be the real carrier of the $[\mathrm{I}]$ ntelligence ordinarily ascribed to the overt act, and think that in this way they explain what makes the overt act a manifestation of [I]ntelligence. They have described the overt act as the effect of a mental happening, though they stop short... before raising the next question - what makes the postulated mental happenings manifestations of [I]ntelligence and not mental deficiency. (1949, 50 emphasis added)

Let us call this the mental appraisal question, which can be formulated generally as follows:

\section{The Mental Appraisal Question}

What makes a given mental act an exercise of a state of Intelligence, rather than not?

It should be clear from $\left[\mathrm{I}_{\mathrm{ACTION}}\right]$ that, according to intellectualism, an individual's act is an exercise of a state of Intelligence only when the individual has a distinct mental state of engaging some propositional content that produces the act. But when we ask about the exercise of that distinct mental state itself, inquiring about the state of Intelligence thereby exercised-specifically, when what is being appraised is a mental act consisting of the exercise of an internal state of engaging propositional content (e.g., considering a proposition, reasoning, and so forth)-Ryle's regress appears to follow in the manner sketched above. But if that is so, then a distinct state of Intelligently engaging a propositional content cannot make a given mental act an exercise of a state of Intelligence, rather than not. What does? Absent a satisfactory, non-regress-inducing intellectualist answer to this question, opponents of the "intellectualist legend" may well regard themselves as supported in their opposition.

While the regress argument is perhaps Ryle's most famous challenge to intellectualism, it may not be the most influential. This brings us to Ryle's second main argument. It is widely thought that intellectualism is counterintuitive, for it violates an intuitive distinction between the theoretical and the practical. Specifically, according to Ryle, it does

not [do] justice to the distinction which is quite familiar to all of us between knowing that something is the case and knowing how to do things.... [Intellectualists] concentrate on the discovery of truths or facts, and they either ignore the discovery of ways and methods of doing things or else they try to reduce it to the discovery of facts. They assume 
that $[\mathrm{I}]$ ntelligence equates with the contemplation of propositions and is exhausted in this contemplation. $(1945,4)$

It should be clear that what Ryle here dubs 'knowing that' represents truth or fact-oriented states consisting in the "contemplation of propositions" (what we have called 'internal states of engaging propositional content') more generally, while 'knowing how' represents action-oriented states regarding "ways and methods of doing things" more generally. Of course, the indicated contrast is most salient when we focus, as Ryle often does, on the case of knowledge that something is the case versus knowledge how to do things, for it is here that we find what intuitively looks to be a clear distinction between merely truth or factoriented theoretical knowledge versus action-oriented practical knowledge. ${ }^{\text {Is }}$ This raises a question, which we will call the practical/theoretical question, of how to account for this intuitive distinction:

\section{The Practical/Theoretical Question}

How are we to understand the distinction between practical knowledge (action-oriented states) and mere theoretical knowledge (merely truth or factoriented states)?

Absent a satisfactory account of the intuitive distinction between practical knowledge and mere truth or fact-oriented knowledge, intellectualism may be accused of failing to do justice to the complex character of mind and action.

We will return to Ryle's regress and this intuitive distinction later. Before moving on, let us briefly consider two of Ryle's less famous-but, arguably, equally significant-arguments against intellectualism. The first of these is broadly epistemological. Because it understands Intelligence in terms of internal (nonpublic) states of engaging propositional content, it seems that intellectualism entails that no amount of external (public) observation could ever enable one to determine whether an intelligence-epithet is applicable in individual cases. Given that all we have to go on in daily life is just such observation, this threatens the very rationality, in daily life, of the ordinary practice of ascribing states and qualities of Intelligence:

15. This type of practical knowledge is not to be confused with what Anscombe (1957, \$32) labeled 'practical knowledge,' by which she meant knowledge of what one is doing intentionally (for example, that I am writing this note); see $\$ 4.3$ for possible connections. Propositional attitudes may be understood as truth or fact-oriented insofar as their propositional contents are bearers of truth and falsity; in this way, propositional attitudes may be true or false. Abilities and dispositions, by contrast, cannot be true or false. A state is merely truth or fact-oriented when it may be true or false and it is not action-oriented. 
According to this theory, external observers could never know how the overt behavior of others is correlated with their mental powers and processes and so they could never know or even plausibly conjecture whether their applications of mental-conduct concepts to these other people were correct or incorrect.... [O] ur characterizations of persons and their performances as intelligent... or as stupid... could never have been made.... (1949, 21 emphasis added; cf. 1949, 54 and 60) ${ }^{16}$

To resist this argument, the intellectualist must answer what we will call the rational ascription question:

\section{The Rational Ascription Question}

What is the basis for the rationality of our ordinary practice of ascribing states and qualities of Intelligence?

Absent a viable answer to this question, intellectualism may be charged with upholding an impoverished view of (our view of) our mental lives.

Let us now turn to Ryle's fourth main argument against intellectualism. The central contention is simple but powerful:

However many strata of knowledge-that are postulated, the same crux always recurs that a fool might have all that knowledge without knowing how to perform....(1945, 8)

Perhaps Ryle's most effective application of this idea occurs in this passage about chess:

We can imagine a clever player generously imparting to his stupid opponent so many rules, tactical maxims, "wrinkles," etc., that he could think of no more to tell him; his opponent might accept and memorise all of them, and be able and ready to recite them correctly on demand. Yet he might still play chess [without Intelligence]. ${ }^{17}(1945,5)$

16. Some commentators have interpreted passages like this one in a way that commits Ryle to an implausible verificationism (cf. Soames 2003, 97-98; Stanley forthcoming-b, 3n.I). Such an interpretation threatens to miss or obscure the genuine question that this and similar passages pose to intellectualism.

17. Ryle's worry is anticipated by Locke in The Conduct of the Understanding: "Nobody is made anything by hearing of rules or laying them up in his memory..., and you may as well hope to make a good painter or musician extempore, by a lecture and instruction in the arts of music 
This raises the delineation question anew. If it is possible, as Ryle suggests, that two such individuals grasp all of the same propositions but only one of them possesses Intelligence (e.g., has knowledge how), then Intelligence does not supervene on propositional attitudes (i.e., the facts about propositional attitudes do not fix the facts about Intelligence). But if that is so, then internal states of engaging propositional content cannot make the difference between behaviors that do, and overtly indistinguishable behaviors that do not, display states of Intelligence. What does? Absent a viable answer to this delineation question, intellectualism may be charged with presenting a wholly inadequate conception of mind and action. ${ }^{18}$

\section{I.3 Anti-Intellectualism}

Ryle's project is not only to challenge the intellectualist legend but also to piece together an alternative conception of mind and its relation to action centered on the idea that "[I]ntelligence-predicates are definable in terms of knowing-how" (1945, 15; 1949, 27-28), where knowing how is held to be equivalent to a particular type of power, that is, a feature of agents typically expressed by a modal auxiliary such as 'can,' 'could,' or 'would': for instance, an ability or disposition.'

According to Ryle $(1949,40-47)$, knowing how to $\varphi$ is not merely a regularity of behavior or a habit, but rather a disposition to $\varphi$ that is (i) trained (i.e., the product of practice, not drill), (ii) trainable (i.e., liable to modification and improvement), ${ }^{20}$ and (iii) multitrack (i.e., it may be exercised in diverse ways, including actions other than $\varphi$ ). ${ }^{21}$ More generally:

and painting, as a coherent thinker or strict reasoner by a set of rules showing him wherein right reasoning consists" (1706/1891, I9).

I8. It is important to distinguish Ryle's "fool argument" from his regress argument. While the latter challenges the right-to-left direction of the intellectualist theses stated above, the former challenges the left-to-right direction. Cf. Fantl (2008, 454-455) and Snowdon (chapter 2).

19. To be sure, it might be true in some sense of 'can' that $x$ can $\varphi$ even though it is not true that $x$ is able or disposed to $\varphi$. Following current practice, we focus on abilities or dispositions, but it is important to emphasize that an account of knowledge how and Intelligence that appealed to such a sense of 'can' may still qualify as a form of anti-intellectualism. (The anti-intellectualist theses stated below and the discussion that follows should be read in this light.)

20. The capacity to learn or to modify and improve one's behavior is often held to be one, if not the primary, mark of intelligence. See, e.g., Nowell-Smith (1960) and Bennett (1964, 34ff.).

2I. It is sometimes suggested that Ryle did not hold that knowledge how to perform some action $\varphi$ is equivalent to a type of disposition to $\varphi$ on the grounds that Ryle $(1949,44)$ maintained that knowledge how is equivalent to a type of disposition "the exercises of which are indefinitely heterogenous" and his examples $(1949,47)$ of such exercises invoke mental actions 
$\left[\mathrm{AI}_{\mathrm{KNOW}-\mathrm{HOW}}\right]$ A state $\sigma$ of an individual $x$ is a state of knowing how to $\varphi$ if and only if $\sigma$ is or involves $x$ 's having a certain type of ability or disposition (e.g., a trained, trainable, multitrack disposition) to $\varphi$, rather than propositional attitudes.

$\left[\mathrm{AI}_{\mathrm{KH}-\mathrm{ACTION}}\right] x$ exercises knowledge how to $\varphi$ in performing an action $\varphi$ if and only if $x \varphi$-s and $x$ has some state $\sigma$ such that (i) $\sigma$ is a certain type of ability or disposition (e.g., a trained, trainable, multitrack disposition) to $\varphi$, rather than propositional attitudes, and (ii) $x$ 's $\varphi$-ing is the actualization of $\sigma$.

These theses are instances of a more general conception of mind and action. This conception, which we will call anti-intellectualism (hence 'AI'), can be understood as the combination of the following two theses about states of Intelligence, and exercises thereof:

$\left[\mathrm{AI}_{\mathrm{MIND}}\right]$ A state $\sigma$ is a state of Intelligence if and only if $\sigma$ is or involves a certain type of ability or disposition (e.g., a trained, trainable, multitrack disposition) to perform some action (or set of actions), rather than propositional attitudes.

$\left[\mathrm{AI}_{\mathrm{ACTION}}\right]$ An individual $x$ exercises a state of Intelligence in performing an action $\varphi$ if and only if $x \varphi$-s and $x$ has some state $\sigma$ such that $(\mathrm{i}) \sigma$ is a certain type of ability or disposition (e.g., a trained, trainable, multitrack disposition) to perform some action (or set of actions), rather than propositional attitudes, and (ii) $x$ 's $\varphi$-ing is the actualization of $\sigma$.

As should be clear, anti-intellectualism entails that the phenomena answering to mental-conduct concepts, including those expressed by adjectives such as 'intelligent' and 'skillful', are grounded in powers-abilities or dispositions to behavior-rather than attitudes. ${ }^{22}$

Anti-intellectualism denies that internal states of engaging propositional content play any role in accounting for Intelligent action. Recitation of "Righty,

such as "deeds imagined" (see, e.g., Weatherson 2007, 436). However, it does not follow from the fact that a disposition D can be exercised in diverse ways, including physical and mental actions other than $\varphi$, that $\mathrm{D}$ is not correctly characterized as a disposition to $\varphi$.

22. It would be illuminating to have a complete theory of abilities or dispositions (Ryle himself seems to have endorsed a conditional analysis; see Maier (2010) for helpful discussion of theories of ability). But no such theory is needed to understand and assess these anti-intellectualist theses-no more than a complete theory of propositional attitudes is needed to understand and assess intellectualism. 
tighty; lefty, loosey" - understood as a state of considering a regulative proposition-before unscrewing a bolt is deemed irrelevant to the Intelligence of the action (or perhaps denied altogether). Propositional attitudes are replaced with abilities or dispositions. As a result, anti-intellectualism seems to introduce the following answers to the mental appraisal, practical/theoretical, delineation, and rational ascription questions:

I. Mental appraisal. What makes a given mental act itself an exercise of a state of Intelligence, rather than not? The answer, according to anti-intellectualism, is that it is a direct exercise of knowledge how, that is, an actualization of a particular type of ability or disposition (for Ryle, a trained, trainable, multitrack disposition to act). Such an actualization, unlike an internal mental act of engaging propositional content (e.g., considering a proposition), is not itself an action that is intelligently or stupidly performed. ${ }^{23}$ Since nothing more than the actualization of such an ability or disposition is held to make a given mental act an exercise of a state of Intelligence, regress is averted.

2. Practical/theoretical. How are we to make sense of the distinction between action-oriented practical knowledge and mere truth or fact-oriented knowledge? The answer, according to anti-intellectualism, is that practical knowledge regarding some activity $\varphi$ - such as knowledge how to $\varphi$-is a particular type of ability or disposition to $\varphi$, whereas mere truth or fact-oriented knowledge regarding $\varphi$ - such as knowledge that $\varphi$ is such and such-is not an ability or disposition to $\varphi^{24}$ To the extent that an ability or disposition to $\varphi$ is plainly an action-oriented state that does not simply collapse our grasp of "ways and methods of doing things" to the mere "contemplation of propositions," such a view successfully accommodates the intuitive distinction between the theoretical and the practical.

\footnotetext{
23. While it may be possible for an ability or disposition to be exercised Intelligently in some cases, as when Gandhi sensibly exercises his disposition to fight systemic injustice by, say, opting to practice various forms of nonviolent resistance rather than guerrilla warfare, the antiintellectualist may hold that certain abilities or dispositions are non-Intelligently exercised. See $\$ 2.2$ for related discussion.

24. Ryle (1949, ch. 9) seems to suggest that the latter is a particular type of ability or disposition to say that $\varphi$-ing is such and such (out loud or in one's head), to imagine that $\varphi$-ing is such and such, and so forth. But such a dispositional account of mere truth or fact-oriented knowledge is wholly optional and is not an essential feature of anti-intellectualism. For relevant discussion, see note 25 , which contemplates an extreme anti-intellectualist position that might embrace such an account; it may also (but need not) deny the practical/theoretical distinction.
} 
3. Delineation. What makes the difference between behaviors that do, and overtly indistinguishable behaviors that do not, display states of Intelligence? The answer, according to Ryle's anti-intellectualism, is that the former behaviors but not the latter are exercises of knowing how, a particular type of ability or disposition, whose detection requires one to "look beyond the performances themselves," but not (as intellectualism seems to imply) to "pry into some hidden counterpart performance enacted on the secret stage of the agent's inner life" (1949, 45).

4. Rational ascription. What is the basis for the rationality of our ordinary practice of ascribing states and qualities of Intelligence? The answer, according to Ryle's anti-intellectualism, is simple:

To find that most people have minds... is simply to find that they are able and prone to do certain sorts of things, and we do this by witnessing the sorts of things they do. Indeed we... discover what specific qualities of intellect and character people have. (1949, 61; cf. 169)

To the extent that observers can determine the presence or absence of the relevant ability or disposition in virtue of witnessing actual performances (in diverse circumstances, on multiple occasions, etc.), the rationality of our ordinary practice of ascribing states and qualities of Intelligence is thus sustained.

\section{Intellectualism after Ryle}

Stripped to its essentials, Ryle's critical project in The Concept of Mind is a philosophical gambit to undercut a traditional view of mind and action by making explicit certain of its commitments and arguing that they have very troubling consequences. Any such project faces the danger of specifying too many details of the target view, for such specification tends to introduce the possibility that the target will evade the criticism proffered by simply tweaking-or, if you prefer, fine-tuning-some of those details, all the while retaining its core contention. Such tweaking is one of the topics of this section. In recent years, it has become clear that intellectualism has available a variety of resources that go unmarked in Ryle's discussion. It has also emerged that an adequate account of knowledge how is not a frivolous philosophical aim. After gesturing at the importance of knowledge how to broader debate about mind and action, we survey some of these resources and explore how they might facilitate intellectualist answers to the delineation, practical/theoretical, mental appraisal, and rational ascription questions. (In the next section, we turn to anti-intellectualism to discuss some of 
the resources to which anti-intellectualists might appeal when attempting to respond to recent intellectualist attacks.)

\section{I Intellectualism, Anti-Intellectualism, and the Importance of Knowing How}

'Intellectualism' and 'anti-intellectualism' are, of course, terms of art that can be used in different ways in different contexts, including the various chapters in this book. (The best policy is to refer to the individual chapters to understand how the author is using the terms.) However, we believe that one of Ryle's most important contributions was to uncover a general, theoretically significant fault line in the theory of knowledge, mind, and action, to which these terms helpfully-and quite naturally-apply. The core contention of the intellectualist side of this line is that states of Intelligence and exercises thereof are at least partially grounded in propositional attitudes. The core contention of the anti-intellectualist side, by contrast, is that states of Intelligence and exercises thereof are grounded in powers (abilities or dispositions to behavior), not in propositional attitudes. That is, with respect to Ryle's fault line, some version of $\left[\mathrm{I}_{\mathrm{MIND}}\right]$ and $\left[\mathrm{I}_{\mathrm{ACTION}}\right]$ seems to be essential to any general intellectualist view, while some version of $\left[\mathrm{AI}_{\mathrm{MIND}}\right]$ and $\left[\mathrm{AI}_{\mathrm{ACTION}}\right]$ seems to be essential to any general anti-intellectualist view. ${ }^{25}$

Now, it is worth observing that if anti-intellectualism is simply the denial of the intellectualist thesis that states of Intelligence are at least partially grounded in propositional attitudes, then it is, strictly speaking, consistent with an approach that does not invoke powers. Be that as it may, what remains distinctive of antiintellectualism is that it does not invoke propositional attitudes; intellectualism, by contrast, does invoke such attitudes. Notice that intellectualists may consistently allow that some states of Intelligence, such as skill, require a corresponding power; they may also allow that mere powers have various roles to play in a

25. Attention to Ryle's fault line also allows us to make sense of an extreme anti-intellectualist position, according to which knowing that depends on knowing how, a position that goes beyond $\left[\mathrm{AI}_{\mathrm{MIND}}\right]$ and $\left[\mathrm{AI}_{\mathrm{ACTION}}\right]$. (One version of this position is endorsed by Hartland-Swann (1956, I14; cf. 1958), who holds that "all cases of knowing that can ultimately be reduced to cases of knowing how." See also Brandom 1994, Haugeland 1998, and Hetherington 2006. Cf. Roland 1958, Ducasse 1964, and Beck 1968.) Generalizing somewhat, such a view asserts the following triad: $\left[\mathrm{AI}_{\mathrm{MIND}}\right]$, $\left[\mathrm{AI}_{\mathrm{ACTION}}\right]$, and the thesis that propositional attitudes and exercises thereof are at least partially grounded in knowing how and other states of Intelligence-and thus, in turn, corresponding abilities or dispositions. It is an interesting question how (or whether) nonextreme anti-intellectualism (which embraces $\left[\mathrm{AI}_{\mathrm{MIND}}\right]$ ) can successfully avoid collapsing into extreme anti-intellectualism. There is also room to contemplate an extreme intellectualist position according to which all mental or agentive powers are at least partially grounded in propositional attitudes. We lack the space to explore these positions here. 
comprehensive theory of mind and action (as well as explanation of particular actions on particular occasions). What remains distinctive of the intellectualist side of the aforementioned fault line is the thesis that all states of Intelligence, including skill, are at least partially grounded in propositional attitudes, regardless of whether a power is somehow required. ${ }^{26}$

At any rate, given the generality of these views, one might wonder why the specific case of knowledge how merits special consideration. In short: why care about knowledge how? Here is one type of answer (several others will emerge at various points later). Suppose for a moment that knowledge how is not grounded in propositional attitudes. Two conclusions would immediately follow. First, intellectualists could not regard knowledge how as a state of Intelligence; however, to the extent that knowledge how is a paradigm example of such a state, this specific case would not be any mere exception to $\left[\mathrm{I}_{\mathrm{MIND}}\right]$ but would undercut its basic motivation. Second, knowledge how would constitute an attractive basis for a general understanding of Intelligent action as not grounded in propositional attitudes, just as Ryle maintained, thereby undercutting $\left[\mathrm{I}_{\mathrm{ACTION}}\right]$. For these reasons, the intellectualist about mind and action cannot easily abandon the idea that knowledge how is grounded in attitudes. Likewise for the anti-intellectualist, who (for parallel reasons) cannot easily abandon the idea that knowledge how is grounded in abilities or dispositions, rather than attitudes. Knowledge how is, in this sense, a hinge on which our general understanding of mind and actionin particular, a satisfactory theory of Intelligence and its manifestation in action-turns. ${ }^{27}$

26. It might be denied that knowing how, skill, and the various other phenomena that we have been calling states of Intelligence are to be given a uniform intellectualist (or anti-intellectualist) account: from this perspective, some of the phenomena are intellectual; others are not. We lack the space to give this perspective the attention it deserves. Prima facie, however, it faces at least two difficulties. First, it not only abandons but also wholly disallows a general theory of Intelligence; yet, insofar as the theory of Intelligence and Intelligent action is still in its infancy, such an extreme verdict may be viewed as premature. Second, and perhaps more importantly, it seems implausible to deny that knowing how, skill, and other states of Intelligence have something important in common; what is needed is an account of this commonality, which just is the project discussed in the text.

27. Further motivation for treating knowledge how as a focal point centers on the practical/ theoretical and delineation questions. Regarding the former, knowledge how is a paradigm of an action-oriented state; understanding such knowledge arguably provides a key to an explanation of the distinction between the theoretical and the practical. Regarding the latter, at a superficial level both the intellectualist and the anti-intellectualist could agree about the proper solution to the delineation question: knowledge how makes the difference between behaviors that do, and overtly indistinguishable behaviors that do not, display states of Intelligence. Of course, this veneer of agreement simply highlights substantial disagreement about how to unpack this solution: to wit, intellectualists and anti-intellectualists are deeply at odds about what knowledge how is. This indicates how understanding knowledge how may play a pivotal 
This goes some distance toward making sense of recent (post-Ryle) emphasis on the specific case of knowledge how. It also invites us to use knowledge how as a model or test case when considering how the intellectualist might respond to the challenges posed by the questions highlighted in \$1.2: the mental appraisal, delineation, practical/theoretical, and rational ascription questions. Let us discuss each in turn.

\subsection{The Mental Appraisal Question}

Recall that the mental appraisal question asks about a given mental act: what makes it an exercise of a state of Intelligence, when it is? Notice that the question does not presuppose that every mental act, or even every mental act in which one engages propositional content, is an exercise of a state of Intelligence-that is, it does not presuppose that all such actions are done or performed Intelligently. Nor should it. While some mental acts, such as reasoning sensibly, may be exercises of Intelligence, other mental acts, such as contemplating or entertaining, need not be. Contemplating or entertaining (i.e., merely thinking about) the proposition that, say, the number of stars in the universe is odd is a clear case of considering a proposition and thus an exercise of a state of engaging propositional content, but it is not obvious what one could mean by saying that it is done or performed Intelligently: "Gilbert contemplated that proposition stupidly" sounds like a category mistake.

Here it is important to bear in mind the difference between an item being a state of Intelligence and an item being an exercise of a state of Intelligence (i.e., being something that is done or performed Intelligently). A given state of engaging propositional content may qualify, by $\left[\mathrm{I}_{\mathrm{MIND}}\right]$, as Intelligent. But it need not thereby qualify as an exercise of Intelligence (i.e., something done or performed Intelligently); to earn that status, it must satisfy $\left[\mathrm{I}_{\mathrm{ACTION}}\right]$, and it is open to the intellectualist to deny, in a given case, that it does. ${ }^{28}$ That there is room for such denial is independently motivated by the stars example, which can be usefully

role in a substantive account of the difference between the Intelligent and the non-Intelligent. The worry that the dispute between intellectualists and anti-intellectualists is not substantive is discussed and rejected in $\$ 4.6$.

28. It is crucial not to conflate two different types of evaluation: (I) whether an act was done correctly or validly (e.g., reasoning according to modus ponens) and (2) whether it was done Intelligently (e.g., reasoning sensibly). That is, we must distinguish between evaluative epithets in general and what Ryle calls the "intelligence-epithets" in particular (and not simply because an act might be done correctly but not Intelligently, as several of Ryle's own examples-involving those who act successfully but not Intelligently-bring out). As emphasized in $\$ \mathrm{I}$ and $\$ 2 . \mathrm{I}$, intellectualism and anti-intellectualism are theses about the latter only. 
contrasted with the case of reasoning sensibly. On the one hand, reasoning sensibly is a state of Intelligence that itself exercises a state of Intelligence (it is reasoning done Intelligently, as implied by the applicability of the intelligenceepithet 'sensibly'); consequently, the intellectualist will hold that reasoning sensibly satisfies both $\left[\mathrm{I}_{\mathrm{MIND}}\right]$ and $\left[\mathrm{I}_{\mathrm{ACTION}}\right]$. On the other hand, merely contemplating or entertaining the proposition that the number of stars is odd is a state of Intelligence that does not itself exercise a state of Intelligence (as implied by the inapplicability of the intelligence-epithet 'stupidly' in the sample sentence at the end of the previous paragraph); consequently, although it may satisfy $\left[\mathrm{I}_{\mathrm{MIND}}\right]$, the intellectualist need not hold that it satisfies $\left[\mathrm{I}_{\mathrm{ACTION}}\right]$.

The intellectualist may exploit these points to deflect Ryle's regress. Intellectualism leads to regress only when clauses (i) and (ii) in $\left[\mathrm{I}_{\mathrm{ACTION}}\right]$ are conjoined with an additional, regress-inducing principle to the effect that the relevant internal states of engaging propositional content are always exercises of Intelligence (i.e., Intelligently done or performed) - and, therefore, must themselves satisfy $\left[\mathrm{I}_{\mathrm{ACTION}}\right]{ }^{29}$ To be explicit, regress ensues when intellectualism is elaborated as follows:

$\left[\mathrm{I}_{\text {ACTION }}+\right]$ An individual $x$ exercises a state of Intelligence in performing an action $\varphi$ (i.e., $x \varphi$-s Intelligently) if and only if $x \varphi$-s and $x$ has some state $\sigma$ such that (i) $\sigma$ is or involves an internal state of engaging propositional content, (ii) $\sigma$ is appropriately causally related to the production of $\varphi$, and $(+) \sigma$ is Intelligently exercised rather than not (i.e., $\sigma$ itself exercises a state of Intelligence).

But intellectualism need not be so elaborated. The condition expressed in $(+)$ is not compulsory, and it should be rejected by intellectualists seeking to avoid regress. But how?

Intellectualists might look to the idea that sometimes one simply acts on one's intellectual state-where, just as in the case of contemplating the stars proposition, the relevant state is not itself something that is Intelligently exercised. This is, in effect, Carl Ginet's contention in the following passage: ${ }^{\circ}$

\footnotetext{
29. Cf. Snowdon $(2003, \$ 4)$.

30. Cf. Stanley and Williamson (200I, \$I), who suggest that the key to Ryle's regress-both understanding it and solving it-is attention to the distinction between intentional action and nonintentional action. As discussed here and in \$I.2, we believe that Ryle's regress centers on the issue of Intelligence and Intelligent action. The class of actions that are Intelligent might not be coextensive with the class of actions that are intentional: for instance, it is plausible to think that when Gilbert contemplates the stars proposition, he does so intentionally, though he does not do so Intelligently. As we shall see, what is needed to answer Ryle's regress is an account of a certain type of non-Intelligently exercised intellectual state.
} 
I exercise (or manifest) my knowledge that one can get the door open by turning the knob and pushing it (as well as my knowledge that there is a door there) by performing that operation quite automatically as I leave the room; and I may do this, of course, without formulating (in my mind or out loud) that proposition or any other relevant proposition. (1975, 7 emphasis in original)

Perhaps in some cases a state of engaging propositional content (in Ginet's example, propositional knowledge that one can get the door open by turning the knob and pushing it, together with propositional knowledge that there is a door there) can be appropriately causally related to the production of ('produce') an Intelligent action, although it is not itself an exercise of Intelligence. The intellectual state-a propositional attitude-is such that it is simply exercised, and its being exercised leads directly (non-Intelligently) to an Intelligent action.

(Some may find it infelicitous or misleading to say that propositional attitudes could ever be "exercised" in action. However, the central idea is that attitudes may be brought to bear on action (i.e., we act on such attitudes), and their being brought to bear on action (acted on) need not itself be an action that is intelligently or stupidly performed. Whether such bringing to bear on action (acting on) is felicitously described as "exercising" is perhaps terminological; indeed, if need be, our usage here may be regarded as technical. On our usage, exercising an attitude is not itself a propositional attitude (i.e., an internal state of engaging propositional content); rather, it is an act of bringing a propositional attitude to bear on action (acting on an attitude), where the subsequent action may be physical or mental. Such exercising is absent from the stars example, which in this respect differs from Ginet's example and the righty-tighty example (from II.I). While the stars example involves a propositional attitude that is not Intelligently exercised, Ginet's example and the righty-tighty example may involve propositional attitudes that are nonIntelligently exercised: that is, in the stars example, the attitude is not exercised (brought to bear on action) at all-one simply has it; in the other two examples, the attitudes are exercised (brought to bear on action) but not Intelligently so. What all of these examples have in common is that they involve propositional attitudes that are not exercised Intelligently. Hence, they differ from the case of reasoning sensibly, which involves an attitude that is exercised Intelligently (viz., sensibly).)

A satisfactory development of this response to Ryle's regress requires an account of the indicated non-Intelligently exercised propositional attitudesattitudes that (i) are states of Intelligence and (ii) produce actions that are exercises of states of Intelligence but (iii) are not themselves exercises of states of 
Intelligence. What are these attitudes? And how can they produce Intelligent actions without themselves being exercised Intelligently?

Let us take a moment to reflect on the issue of the non-Intelligent exercise of attitudes that are themselves Intelligent. (Possible characterizations of the relevant attitudes themselves will be discussed in the next section.) There are at least two different approaches that the intellectualist might take to this phenomenon. According to a personalist view, the relevant attitudes are exercised through a non-Intelligent act that is performed by the person, for example, the act of applying or utilizing one's attitude. Thus, the relevant attitudes are not Intelligently exercised; rather, they are simply applied or utilized, and their being applied or utilized produces an Intelligent action. ${ }^{31}$ According to a subpersonalist view, the relevant attitudes are exercised through a non-Intelligent act that occurs at the subpersonal level (i.e., an act that is not performed by the person), for example, the act of deploying or triggering an attitude (cf. Fodor 1968, 629 and 632-633; Stanley forthcoming-b, 15-17). Thus, one does not Intelligently exercise the relevant attitudes; rather, they are simply deployed or triggered, and their being deployed or triggered produces an Intelligent action. Naturally, a bybrid view will hold that the relevant attitudes are in some cases non-Intelligently exercised through an act that is performed by the person and in other cases through an act that occurs at the subpersonal level. (The hybrid view may be rendered attractive by the thought that the righty-tighty case seems to involve a person applying her knowledge of a regulative principle, whereas in Ginet's example, propositional knowledge regarding the door arguably could be simply triggered or deployed subpersonally.) To the extent that these views are able to explain how the relevant attitudes can be non-Intelligently exercised, such views would play a crucial role in helping to elaborate intellectualism in a way that averts regress..$^{32}$

In a moment, after considering (in \$2.3) several intellectualist answers to the practical/theoretical question, we will be able to articulate (in \$2.4) how

\footnotetext{
31. Such applying or utilizing might be understood in terms of what O'Shaughnessy (1980, ch. Io) refers to as 'sub-intentional actions,' such as agentively but absent-mindedly strumming one's fingers, perhaps in the way suggested by Steward $(2009,308)$ : "they are... our doings, even though they are not the products of our intentions" nor the results of "any antecedent thinkings, wishings, plannings, or the like." In general, a personalist view requires denial of Ryle's (1945, 4) assertion that "whatever 'applying' may be, it is a proper exercise of [I]ntelligence," if this is meant to imply that each and every act of applying (or utilizing) is an exercise of Intelligence. For relevant discussion, see Parry (1980, 389-390), who suggests that Ryle's view that applying is a proper exercise of Intelligence implies that anti-intellectualism is itself guilty of regress.
}

32. Ryle would presumably object to the subpersonalist and hybrid views, which seem to violate the tenet that the locus of Intelligence is always the person or agent. Cf. Nagel (1969) and, e.g., Korsgaard (1999). 
intellectualism might attempt to use these ideas to dispel Ryle's regress. But first, it is worth pausing to notice that the personalist and subpersonalist views described here embody an intellectualist approach to the exercise of Intelligence that is, at a certain level of abstraction, of a piece with Ryle's own anti-intellectualist answer to the mental appraisal question, outlined in \$1.3. The central difference is that whereas anti-intellectualism invokes abilities or dispositions such that their exercise is not itself an action that is Intelligently performed, ${ }^{33}$ intellectualism invokes attitudes such that their exercise is not itself an action that is Intelligently performed. In both cases, one encounters a phenomenon-a type of power (ability, disposition) or a type of state (attitude) - that is non-Intelligently actualized or exercised, and its being so actualized or exercised leads directly to Intelligent action.

\subsection{The Practical/Theoretical Question}

Of course, this last clause serves to reinforce the point, noted a moment ago, that a complete intellectualist answer to Ryle's regress requires a characterization of the relevant attitude. What is needed is an intellectual state that, in addition to being capable of non-Intelligent exercise, fits the profile Producer of Intelligence: a type of propositional attitude that produces Intelligent action when (non-Intelligently) exercised. Of course, filling this lacuna is tantamount to identifying a propositional attitude that is practical or action-oriented rather than merely theoretical. In this way, a response to Ryle's regress looks to be inseparable from an answer to the practical/theoretical question-which, from the perspective of intellectualism, can be addressed only by an attitude that is in some sense truth or fact-oriented (insofar as it is an internal state of engaging propositional content), but not merely so. What could such an attitude be?

Now, at one level of description, intellectualism might simply offer a broadly functional characterization of the relevant attitude: ${ }^{34}$ for example, it is a type of state whose nature or role is to produce Intelligent action under certain conditions, namely, when exercised. Of course, for this to be a satisfactory intellectualist response to the practical knowledge question, we must have reason to think that

\footnotetext{
33. Recall note 23 .

34. Cf. Craig (1990, I53), who suggests that the central idea behind the intellectualist approach is, roughly, that "the change from 'that' to 'how' marks the fact that we are dealing with [an] information [al state] of the type which characteristically enables a certain kind of action." It is sometimes suggested that acknowledging a distinction between action-oriented states and mere truth or fact-oriented states suffices to establish that knowledge how_or, more generally, Intelligence-is not an intellectual matter, thus vindicating anti-intellectualism. We hope that the present discussion makes clear why this is mistaken.
} 
this state is or involves a propositional attitude (or combination of propositional attitudes). We must also be told how the relevant state could satisfy this functional characterization without simply collapsing into an anti-intellectualist disposition to behavior. Addressing these issues looks to be among the most pressing tasks facing intellectualism.

Here, briefly, are three approaches that might be seen as taking steps in this direction. First, building on a suggestion by Jason Stanley and Timothy Williamson (200I), one might hold that practical knowledge involves contemplating or entertaining a proposition under a "practical mode of presentation," as opposed to a nonpractical-for instance, merely theoretical-mode of presentation. ${ }^{35}$ Second, following John Bengson and Marc Moffett (2007; chapter 7), the intellectualist might hold that practical knowledge involves understanding a way of acting, where such understanding-which essentially requires reasonable mastery of certain concepts-is a state that is poised to guide successful, intentional action. A third version of intellectualism might exploit (Ryle's colleague) Herbert Haberly Price's $(1946,36)$ notion of familiarity with a universal, holding that practical knowledge involves familiarity with a "practical" universal, for example, an action-type. ${ }^{36}$ (We will return to Price's discussion of familiarity with a universal in \$2.5.)

Of course, these approaches do not entail that there is an exclusive or fundamental distinction between knowledge that something is the case and knowledge how to do things. Nevertheless, to the extent that one or another of the indicated notions - a practical mode of presentation, understanding a way of acting, familiarity with a practical universal, or some combination thereof-allows us to identify a type of attitude that, while practical, can be fully characterized without implicitly or explicitly collapsing into an antiintellectualist ability or disposition to behavior, the result would be an intellectualist-friendly account of the intuitive distinction between practical knowledge (action-oriented states) and mere theoretical knowledge (merely truth or fact-oriented states).

35. Cf. Williamson $(1999,44)$ : “one's grasp of the propositional content may be distinctively practical (' $\varphi$ now!'; ' $\varphi$ like this!').” For critical discussion of the notion of a practical mode of presentation, see Koethe (2002), Schiffer (2002), Rosefeldt (2004), Fantl (2008, 460ff.), and Williams $(2008, \$ 5)$.

36. Cf. Carr (1981a, 60-61), who focuses on knowledge of rules of a practice or "relations between prescriptions," and Gibbons (2001,590), who suggests that "knowing how is something like having a non-accidentally effective action plan.” In a similar vein, Annas (200I, \$\$4-6) emphasizes the importance of understanding the subject matter of an area of expertise, which she relates to the Platonic notion of grasping a Form - with which Price's notion of familiarity with a universal likewise bears affinities. 


\subsection{Intellectualism and Ryle's Regress, Continued}

We are now in a position to see how intellectualism might seek to avoid regress.

As indicated in \$2.I, knowledge how may serve as our test case. Suppose (for purposes of illustration) that the intellectualist holds, in conformity with $\left[\mathrm{I}_{\mathrm{KH}-\mathrm{MIND}}\right]$ (and $\left[\mathrm{I}_{\mathrm{MIND}}\right]$ ), that $x$ knows how to $\varphi$ if and only if $x$ possesses intellectual state $\alpha^{*}$, where $\alpha^{*}$ is appropriately practical - that is, $\alpha^{*}$ is action-oriented; for example (recalling the options canvassed in \$2.3), it involves contemplation of a proposition regarding $\varphi$-ing under a practical mode of presentation, understanding a way of $\varphi$-ing, or familiarity with the action-type $\varphi$. Now, let $\alpha$ be an action, such as pruning trees, that an individual might know how to perform. Then $\left[\mathrm{I}_{\text {KH-ACTION }}\right]$ (and $\left[\mathrm{I}_{\mathrm{ACTION}}\right]$ ) will be true just in case the following holds: $x$ exercises knowledge how to $\alpha$ in performing $\alpha$ if and only if $x$ performs $\alpha$ and (i) $x$ has $\alpha^{*}$ and (ii) $\alpha^{*}$ is appropriately causally related to the production of (again, 'produces') $\alpha$. As we saw in $\$ 2.2$, a subpersonalist version of intellectualism will hold that $\alpha^{*}$ is deployed or triggered but not Intelligently so; hence, $\alpha^{*}$ is knowledge how (i.e., knowledge how to $\alpha$ ), but the deployment or triggering of $\alpha^{*}$ does not exercise knowledge how, nor any other state of Intelligence. Analogously for a personalist version of intellectualism, according to which $\alpha^{*}$ is applied or utilized. Let ' $\alpha^{* *}$ signify the act of deploying, triggering, applying, or utilizing $\alpha^{*}$. Since $\alpha^{* *}$ does not exercise any state of Intelligence, $\left[\mathrm{I}_{\text {KH-ACTION }}\right]$ does not apply to it; consequently, in neither casesubpersonalist nor personalist-does the intellectualist encounter a need to postulate any further intellectual state $\left(\alpha^{* * *}\right)$ that produces $\alpha^{* *}$. On both views, $\alpha^{* *}$ (the act of deploying, triggering, applying, or utilizing $\alpha^{*}$ ) is not itself something that is Intelligently done or performed (i.e., it does not exercise a state of Intelligence), and $\alpha^{*}$ is appropriately practical: it is a type of intellectual state such that if its deployment, triggering, application, or utilization produces $\alpha$, then $\alpha$ exercises knowledge how to $\alpha$. In this way, by combining an appropriate characterization of the relevant intellectual state with a personalist or subpersonalist view of its non-Intelligent exercise, regress is averted.

The same story might be told mutatis mutandis for other states of Intelligence, such as intelligence and skill, and its overall success will depend on the success of its central characters, discussed in $\$ \$ 2.2-3$.

\subsection{The Delineation Question}

Insofar as an intellectual state that fits the profile Producer of Intelligence plays a crucial role in a general intellectualist account of the difference between the Intelligent and the non-Intelligent, an intellectualist answer to the mental appraisal and practical/theoretical questions must be developed in tandem with 
an answer to the delineation question. What makes the difference between behaviors that do, and overtly indistinguishable behaviors that do not, display states of Intelligence? As we saw in \$1.3, an answer to this question must display an appropriate sensitivity to Ryle's fool argument, which contends that two individuals might have all of the same propositional attitudes with respect to some activity $\varphi$ (e.g., chess), yet one possesses while the other lacks Intelligence and knowledge how with respect to $\varphi$. There are several ways that the intellectualist might try to respond to the fool argument and answer the delineation question. ${ }^{37}$ We shall consider three.

First, the intellectualist might draw inspiration from Stanley and Williamson's (200I) appeal to a practical mode of presentation in the case of knowledge how (mentioned in \$2.3). On this approach, one individual possesses while the other individual lacks knowledge how to $\varphi$ because only one of them entertains the relevant proposition regarding $\varphi$ under a practical mode of presentation. Other states of Intelligence could be treated analogously, perhaps as summoning their own distinctive modes of presentation.

Second, the intellectualist might utilize Bengson and Moffett's (2007; chapter 7) appeal to understanding (also mentioned in \$2.3). The importance of understanding was perhaps first stressed by Descartes, who wrote in Discourse on Method that a careful study of mindless automata as compared with those beings with minds, such as ourselves,

would reveal that [the automata] were not acting through understanding [connaissance] but only from the disposition of their organs..$^{8}$ (1637/1984, I40 emphasis added)

On the version of the understanding-based approach suggested by Bengson and Moffett, one individual possesses while the other individual lacks knowledge how to $\varphi$ because only one of them understands a way of $\varphi$-ing, where such understanding essentially requires reasonable mastery of concepts in a (possibly implicit) conception of that way. Other states of Intelligence could be held to require reasonable conceptual mastery in much the same way.

\footnotetext{
37. One option that we do not elaborate consists in denying (or rephrasing) Ryle's fool intuition, holding that there would in fact be some propositional attitude that one individual possesses but the other lacks. Of course, the intellectualist would need to provide fairly compelling reasons for such denial; she would also owe an explanation of the original intuition, assuming it persists.

38. See Erion (200I) for discussion of Cartesian "tests" for intelligence and their connection to the famous Turing Test.
} 
Third, the intellectualist might make use of Price's discussion of the role of familiarity with a universal in intelligent action:

Sometimes... familiarity with a universal enables... an actual real-life instance. If you are up in an aeroplane and ask the pilot what a stall is, he may answer by pulling back the control stick and actually doing one. His familiarity with that universal has enabled him to produce an actual instance of it.... This indeed is one of the most striking ways in which familiarity with a universal can show itself. It also illustrates the very intimate connexion which there is between cognition and action.... Our familiarity with the universal, a cognitive state, overflows of itself into an activity which is practical. This is just what we call an intelligent action. ${ }^{39}$ $(1946,36)$

This idea could be applied to other states of Intelligence as well. On such an approach, one individual possesses while the other individual lacks Intelligence because only one of them is familiar with the relevant universal. (For example, in the case of knowledge how to $\varphi$, the relevant universal might be the actiontype $\varphi$.)

These three types of response to the fool argument open up three types of answer to the delineation question. Specifically, what makes the difference between the Intelligent and non-Intelligent may be said to be a combination of propositional attitudes plus (i) the mode of presentation under which the propositional contents of the relevant attitudes are entertained, (ii) understanding (hence reasonable conceptual mastery), or (iii) familiarity with a relevant universal. These intellectualist answers to the delineation question can be usefully compared to Ryle’s own anti-intellectualist answer, outlined in \$r.3. Whereas anti-intellectualism invokes a special type of ability or disposition when accounting for the distinction between the Intelligent and the non-Intelligent, intellectualism invokes a special type of attitude when accounting for this distinction. Insofar as this special type of attitude just is a state that fits the profile Producer of Intelligence, the result would be a uniform answer to the mental appraisal, practical/theoretical, and delineation questions.

39. Price seems to use 'cognition' and 'cognitive' in a traditional sense that opposes the cognitive to the sensory; we will follow this usage here and below. As this passage illustrates, Price's discussion of the relation between cognition and action is extremely rich and suggestive; we lack the space to do it justice here. Price goes on to consider several other ways of manifesting one's familiarity with a universal: for example, in addition to doing (showing, demonstrating) it, one might imagine it, draw it, describe it, or recognize it when it is manifested by others. 


\subsection{The Rational Practice Question}

While the mental appraisal, practical/theoretical, and delineation questions force the intellectualist to theorize about the metaphysics of propositional attitudes, viz., specifying what could make it the case that certain non-Intelligently exercised attitudes have the profile Producer of Intelligence and serve to make the difference between the Intelligent and the non-Intelligent, answering the rational ascription question is, by contrast, a largely epistemological project. There are two main epistemological strategies the intellectualist might pursue when seeking to provide a rational basis for our ordinary practice of ascribing states and qualities of Intelligence. We begin with a strategy that focuses on observation and then turn to a strategy that focuses on inference. ${ }^{40}$

The observation strategy has two steps: the first step is to accept the requirement, evidently endorsed by Ryle, that the indicated practice can be rational only if states and qualities of Intelligence are somehow objects of public observation; the second step is to develop a (perhaps nontraditional) account of such observation-of how such things are observed (perceived), if intellectualism is true. For example, the observation intellectualist might accept a "rich" view of the objects of perception, allowing that we perceive states and qualities of Intelligence in much the same way that some have said we perceive semantic properties (Peacocke 1992, 89-90) or natural kind properties (Siegel 2006), namely, through perceptual engagement whose scope is improved or increased (albeit still in some sense noninferentially) by other features of our epistemic situation (e.g., our conceptual capacities or background knowledge). Or the observation intellectualist might pursue John McDowell's (1982/1998, 387 ) suggestion that facts regarding internal states of mind can be perceived indirectly (yet still in some sense noninferentially) via the direct perception-"disclosure to experience"-of certain publicly observable features, for example, their expression or manifestation:

The idea of a fact being disclosed to experience is in itself purely negative: a rejection of the thesis that what is accessible to experience falls short of the fact in the sense... of being consistent with there being no such fact... [One] application of the idea... seems appropriate in at least some cases of knowledge that someone else is in an "inner" state, on the basis of experience of what he says and does. Here we might think of what is directly available to experience in some such terms as 'his giving expression to his being in that "inner" state': this is something that, while not

40. There is, of course, room for a hybrid approach that allows both observation and inference. 
itself actually being the "inner" state of affairs in question, nevertheless does not fall short of it in the sense I explained.

These are just two examples—rich and indirect-of how, in broad outline, the intellectualist might try to carry out step two in the observation strategy.

The inference strategy also has two steps: the first step is to reject the requirement that our ordinary practice of ascribing states and qualities of Intelligence can be rational only if such states and qualities are somehow objects of public observation; the second step is to develop an alternative account of the rational basis of this practice in terms of the rational character of ordinary inferences regarding such states and qualities. For example, the inference intellectualist might hold that we rationally infer states and qualities of Intelligence in much the same way that some have said we rationally infer, say, electrons, namely, through a cogent abductive inference based on perception of publicly observable phenomena. Another option is to revisit the plausibility of much-debated appeals to analogical inference, whose viability Ryle consistently challenged. Or to cite just one more example, the inference intellectualist might pursue the possibility of a valid deductive inference based on perception of publicly observable phenomena, together with (possibly tacit or implicit) beliefs whose contents somehow invoke principles of rational or folk psychology. And so on for various other inferentialist responses to skepticism about other minds.

The observation and inference strategies introduce answers to the rational ascription question that are quite similar to Ryle's own anti-intellectualist answer, outlined in \$I.3. In both cases, we detect items that are not wholly overt. Whereas anti-intellectualism allows that we detect abilities or dispositions in virtue of witnessing actual performances (in diverse circumstances, on multiple occasions, etc.), intellectualism allows that we detect attitudes in virtue of witnessing such performances. Either way, we manage to "look beyond the performance itself" to a power (ability, disposition) or intellectual state (attitude) of the individual that is distinct from any particular overt behavior.

The foregoing suggests how intellectualists might answer questions about the appraisal of mental acts, the intuitive distinction between the theoretical and the practical, the delineation of Intelligent action, and the rational basis for ascriptions of states and qualities of Intelligence. Obviously, much depends on the details, which remain to be spelled out (several of this book's chapters can be regarded as contributing to this project). But we hope that this discussion indicates the subtlety and richness of the surrounding issues, as well as some of the resources available to those wishing to elaborate and defend intellectualism. ${ }^{4}$

4I. These and other resources may be used to develop responses to objections to particular versions of intellectualism (of which there are many; see, in particular, Cath chapter 5), which we 


\section{Anti-Intellectualism after Ryle}

Anti-intellectualists likewise possess a variety of resources that may be used to elaborate and defend their position against recent (post-Ryle) attacks. This section explores some of the issues surrounding four such attacks, each of which can be understood as suggesting that anti-intellectualism is unable to satisfactorily answer certain questions about mind and action. We first identify these questions and sketch how they are, or might be, answered by intellectualists; then we briefly discuss how they might also be answered by anti-intellectualists. While the discussion is concerned with states of Intelligence in general, for the sorts of reasons discussed in $\$ 2$.I, we often focus on knowledge how, treating it as a model or test case.

\section{I Four Arguments against Anti-Intellectualism}

One of the main arguments against anti-intellectualism is that knowledge howand hence Intelligence-can, and sometimes does, come apart from abilities and dispositions. On one hand, coaches, instructors, and other authorities have been said in some cases to know how to do things-and hence to possess Intelligence with respect to certain activities-that they are not themselves able or disposed to do. For example, Jeffrey King provides the example of a ski instructor who teaches his students how to do complex jumps that he himself is unable or indisposed to perform (see Stanley and Williamson 200I, 416), and Paul Snowdon (2003, 8) describes a situation in which a master chef loses his arms and, in turn, the ability or disposition to cook but nevertheless retains culinary know-how. On the other hand, the lucky and the ignorant have been said in some cases to be able or disposed to do things that they do not themselves know how to do-and, moreover, to exercise such an ability or disposition in actions that wholly lack Intelligence. For example, David Carr $(1979,407)$ offers the case of a modern dancer who unwittingly performs a semaphore version of Gray's "Elegy," and Katherine Hawley $(2003,27)$ presents a scenario involving an uninformed hiker who mistakes falling snow for water and subsequently escapes an avalanche by making swimming motions.

do not consider here. Additional resources include, for example, allowing variation among the relevant propositional attitudes; allowing variation among the relevant propositional contents of the attitudes; recruiting a notion of nonconceptual content; emphasizing the role of demonstrative concepts (cf. McDowell's (1994, 1996, 2007, and elsewhere) notion of "situation-specific conceptual articulation"); providing a pragmatic, contextual, or epistemic explanation of anti-intellectualism's focus on abilities or dispositions; questioning alleged or assumed equivalences between knowing how and various other phenomena (e.g., so-called procedural knowledge, discussed in $\$ \$ 4.5-6$ ); and so forth. Some of these options are developed in the chapters of this book. 
Although such examples have typically focused on the specific case of knowing how, each may be modified to probe other states of Intelligence as well. To illustrate, it seems clear that Carr's dancer and Hawley's hiker, who are able to perform their respective activities while lacking the relevant knowledge how, also lack the relevant intelligence and skill: the dancer does not intelligently perform a semaphore version of Gray's "Elegy," and the hiker is not skilled at escaping avalanches (though she may be skilled at making swimming motions). Likewise for other intelligence-epithets: the hiker no more escapes the avalanche idiotically than she does sensibly or cleverly (though she does, of course, escape luckily). If this is correct, then these examples demonstrate the possibility of ability without intelligence, skill, sensibleness, and cleverness.

It is less straightforward to uncover a gap in the other direction; indeed, many theorists deny that such states of Intelligence can be present in the absence of corresponding ability. Yet, might an individual be a clever (sensible, intelligent, skilled) teacher, but because she develops a debilitating condition be no longer able to teach? Or consider Snowdon's master chef, who has lost his arms: might he still retain his culinary skills? Perhaps not, given that he is now unable to cook. But one might imagine an observer remarking on how tragic it is that the master chef will no longer be able to cook; her interlocutor responds that, fortunately, the master chef's virtuosity will not be wasted, for the master intends to impart his culinary skills by mentoring students who show promise of achieving expertise comparable to his own.

It is possible to view discussion of these cases (and many others like them) as contributing little more than putative counterexamples to anti-intellectualism: if states of Intelligence can come apart from abilities and dispositions, as these cases might be taken to suggest, then the former cannot be grounded in the latter. An alternative-and, perhaps, theoretically more fruitful-perspective consists in seeing them also as challenges to the anti-intellectualist's answer to the delineation question, outlined in $\$ \mathbf{r}$.3. Such cases seem to suggest that it is possible that two individuals have all of the same abilities or dispositions to behavior, but only one of them has knowledge how. But if this is so, then knowledge how does not supervene on abilities or dispositions (i.e., the facts about abilities and dispositions do not fix the facts about knowledge-how), in which case abilities or dispositions cannot make the difference between behaviors that do, and overtly indistinguishable behaviors that do not, display states of Intelligence. What does?

Recalling the discussion in $\$ \$ 2.2-5$, the intellectualist may point to a combination of propositional attitudes plus (i) mode of presentation, (ii) conceptual understanding, or (iii) familiarity with a relevant universal. Individuals who know how to $\varphi$ while lacking the ability or disposition to $\varphi$ still possess such intellectual states, whereas individuals who have the ability or disposition to $\varphi$ 
but do not know how to $\varphi$ lack such intellectual states. It remains to be seen whether the anti-intellectualist can likewise explain the cases in question. Absent such an explanation, which is to say absent a satisfactory answer to the delineation question, opponents of anti-intellectualism may continue to view their opposition as well grounded.

A second type of argument against anti-intellectualism focuses on the role of knowledge how - and hence Intelligence-in phenomena such as practicing complex intentional actions. Coming to possess a disposition or ability to perform a certain action in some cases requires practicing that action; in this vein, Aristotle famously suggested in the Nichomachean Ethics,

For the things we have to learn before we can do them, we learn by doing them, e.g. men become builders by building and lyreplayers by playing the lyre. (350 B.C.E./1908, 1103a32)

Even if Aristotle's remark does not apply across the board, it is difficult to deny that, at least in some cases of complex intentional action (e.g., cooking a soufflé, dancing the tango, shaving, dunking a basketball, surfing, tying a complicated knot, making putts), we practice with the purpose of eventually acquiring a novel disposition or ability. In such cases, however, it seems that we must already know how to do what we are not yet disposed or able to do. (Or, at least, it must be possible to do them sillily or stupidly, and thus Intelligently, prior to acquiring the ability or disposition sought. But let us focus on the role of knowledge how in particular.) Given these actions' complexity, if we did not already know how to perform them, it is not clear how we would go about practicing them..$^{42}$ This raises what we will call the complex practice question:

\section{The Complex Practice Question}

How are we to explain the possibility of practicing complex intentional actions that we are not yet able or disposed to perform?

If knowledge how to $\varphi$ involves a (possibly tacit or implicit) attitude whose propositional content represents a way of $\varphi$-ing, as intellectualism allows, then

\footnotetext{
42. Cf. Bengson and Moffett $(2007,34)$. We at least do not recommend practicing shaving prior to knowing how to shave! Snowdon $(2003,20)$ observes that knowledge how to $\varphi$ may precede practicing $\varphi$-ing: "we very often [come] to know how to do something without any practice. Just a glance in the room where I am was enough for me to realise how to reach the chair I am sitting in. I certainly did not need to practice reaching it." This observation may also pose a challenge to Ryle’s emphasis on training, discussed in \$1.3.
} 
even prior to being able or disposed to $\varphi$, one may already have in one's cognitive possession, as it were, a way of $\varphi$-ing. Conscious awareness, attention, and concentration may then be applied to individual movements in attempting or endeavoring to act in this way, for example, by coordinating particular parts of the body or executing a series of steps; such a conscious process, though perhaps unnecessary once one has mastered $\varphi$-ing (at which point $\varphi$-ing may become "automatic"), constitutes practicing $\varphi$-ing. Fred Dretske begins to describe this process in "Where Is the Mind When the Body Performs?":

We begin the learning process aware of the fingers, the arms, the legstheir position and movements. Precisely timed sequences have to be coordinated and the only way to coordinate them is by awareness of the individual movements. In learning to shoot a lay-up, for example, one has to concentrate on elevating from the left foot as one shoots with the right hand. In learning to swim, one has to concentrate on, think about, be aware of, one's breathing in order to time inhalations with the brief interval during which the nose and mouth are out of the water. (1998)

In this way, knowledge how might be said to enable complex practice: coordination of individual movements through (as Dretske describes) awareness of, concentration on, and thinking about particular parts of the body and their role in the execution of the action. Because anti-intellectualism understands states of Intelligence in terms of abilities or dispositions, it entails that knowledge how to $\varphi$ cannot precede a disposition or ability to $\varphi$. Prima facie, this is problematic. To the extent that practicing complex intentional actions requires knowledge how to do what we are seeking to be (and thus are not yet) disposed or able to do, as suggested above, this threatens the very possibility of such practice. Absent a viable answer to the complex practice question that somehow manages to dissolve this threat, anti-intellectualism may be charged with offering an untenable view of the relation between mind and action.

A third argument against anti-intellectualism highlights an intuitive distinction between practical knowledge and various other practical phenomena, such as knacks, which do not involve the same type of rational, epistemic achievement. Here, for example, is Julia Annas:

Either "knowing how" involves "knowing that" or it does not. If it does not, then what we think of as practical knowledge is being construed as a kind of inarticulate practical knack, an ability to manipulate the world which is not at a sufficiently rational level to be judged epistemically. (200I, 248) 
It should be clear that Annas is here using 'knowing how' to represent states of practical knowledge more generally, including skill and expertise, and 'knowing that' to represent truth or fact-oriented states more generally (once again, what we have called 'engaging propositional content'). Her idea is that the cognitive character of genuine skill or expertise cannot be accommodated by an approach that focuses solely on successful performance, which can also be found in knack and various potentially non-Intelligent behaviors, such as reflexes and instinctual responses. To appreciate an individual as possessing practical knowledge ("knowing how') and not merely as a "muddler or dabbler" (Annas 200I, 244) who has a non-Intelligent knack, we must, Annas suggests, look beyond the individual's powers ("an ability to manipulate the world") to something that could make sense of her rational, epistemic achievement: namely, her truth or fact-oriented states ('knowing that'), as the intellectualist recommends. ${ }^{43}$ The challenge that this suggestion poses to anti-intellectualism has its source in what we will call the knowledge/knack question:

\section{The Knowledge/Knack Question}

How are we to understand the distinction between states of practical knowledge (in particular, knowing how, skill, and expertise) and mere knacks?

This question is related to but distinct from the delineation question. While the delineation question asks about the difference between behaviors that do, and those that do not, display states of Intelligence, the knowledge/knack question asks about the states that are held to underlie and explain that difference. The knowledge/ knack question can thus be regarded as seeking an explanation of the very Intelligence of those states. ${ }^{44}$ What is wanted is an understanding of how or why states of practical knowledge embody such Intelligence, which is not present in all

43. Cf. Setiya (2008, 405ff.) and Bengson and Moffett (chapter 7); see also Bennett (1964) on the differences between genuine intelligence and "fake" and "frozen" intelligence. Annas (200I, 244; cf. chapter 4) connects the distinction between practical knowledge and mindless or absentminded knack to the issue of learning and practice: "A skill is intellectually complex and requires thought to acquire; it is not just something which can be picked up casually from experience. Hence, it is contrasted with a "knack"..., which you can pick up just by copying other people without thinking much about it." Cf. Dewey (1922, 173 and 178), who contrasts intelligence and intelligent action with impulse and "treadmill activity" and records the worry that "practical work done by habit and instinct in securing prompt and exact adjustment to the environment is not knowledge, except by courtesy."

44. The explanandum here is captured by the striking images of Solomon Andrée's crashed balloon, the Eagle, which manage to depict the genuine Intelligence of practical knowledge through an important style of breakdown, yet against the backdrop of an even more significant type of achievement. 
action-oriented states. Viewed another way, an adequate theory must distinguish not only between Intelligent and non-Intelligent behaviors but also between, for example, Intelligent-powers and mere knack-powers (e.g., the muddler's mere capacity to act successfully). Intellectualists propose to account for this distinction-and, in turn, address the knowledge/knack question-by citing propositional attitudes (together with, e.g., mode of presentation, conceptual understanding, or familiarity with a relevant universal, as discussed above), which are held to be the source of Intelligence. Anti-intellectualists must provide an alternative account of the source of Intelligence. Absent such an account, which is to say absent a satisfactory answer to the knowledge/knack question, anti-intellectualism may be accused of offering a seriously incomplete account of mind and action.

A fourth type of argument against anti-intellectualism has focused on the syntax and semantics of ascriptions of states of Intelligence, in particular, knowledge how. Stanley explains the rationale behind concern with such linguistic issues as follows:

Suppose one produces an analysis of knowing how to do something. Surely, it would be a worry with such an analysis if there is no correct compositional semantics of English according to which ascriptions of knowing how to do something express that analysis. If there were no plausible compositional semantics for English ascriptions of knowing how that assigned to them one's favored analysis, then that would show that one's analysis could not possibly be what English speakers mean when they use such ascriptions. (forthcoming-a)

This introduces what we will call the linguistics question:

\section{The Linguistics Question}

What is the correct semantics (intensional or extensional) for ascriptions of knowledge how and other states of Intelligence?

It is widely held that contemporary theories of the semantics of embedded questions, supported by corresponding syntactic analysis, indicate that a sentence such as 'Gilbert knows how to prune trees' ascribes to the subject (here, Gilbert) propositional knowledge of the answer to a question (here, how to prune trees), no less than does 'Gilbert knows where to prune trees' or 'Gilbert knows when to prune trees.'45 Thus

45. Cf. Brown (1970), Vendler (1972, ch. 5), Ware (1973, I56), Hintikka (1975, 1992), White (1982, ch. 2), Stanley and Williamson (200I), Braun (2006; chapter 10), Schaffer (2007, 
it is said that intellectualism is able to accurately specify what English speakers mean when they use such knowledge-wh constructions (knowledge how, where, when, who, etc.). This applies pressure to anti-intellectualism. In the absence of a plausible semantics according to which ascriptions of knowing how actually ascribe to the subject an ability or disposition to perform the relevant behavior, anti-intellectualism may be accused of changing the subject: away from our nontechnical, "familiar and everyday" notion (with which Ryle himself was originally concerned; see, e.g., 1949, 7-9 and 62) toward something else altogether.

\subsection{The Delineation Question}

Let us consider how the anti-intellectualist might respond to the challenges posed by the questions highlighted in the previous section, beginning with the delineation question. What makes the difference between behaviors that do, and overtly indistinguishable behaviors that do not, display states of Intelligence? We have seen that those cases in which knowing how and abilities or dispositions appear to come apart cast doubt on the anti-intellectualist's proposal that the Intelligent and the non-Intelligent can be distinguished in terms of abilities or dispositions. ${ }^{46}$ To dispel these doubts, the anti-intellectualist might resolve to tweak-adjust or finetune-some of the details of her position, while nevertheless retaining its core contention, namely, that knowledge how and other states of Intelligence are grounded in a type of power. ${ }^{47}$ This involves viewing the putative counterexamples in the way recommended by Daniel Bonevac, Josh Dever, and David Sosa:

2009b), Brogaard (2009; chapter 6), and Stanley (2011). See, in particular, Groenendijk and Stokhof $(1982,1984,1997)$ and Karttunen (1977).

46. It is important to ensure that the cases do not merely show that knowledge how one $\varphi$-s (or knowledge how $\varphi$-ing is done, knowledge how it is that $\varphi$ is performed, or knowledge of what it takes to $\varphi$ ) comes apart from abilities or dispositions - to the extent, of course, that the former differs from knowledge how to $\varphi$ (cf. Hornsby 1980, 84; Noë 2005, 284 n. 4; Hetherington 2006, 7 I n. 2 and \$II; and Bengson and Moffett 2007, \$I and chapter 7, \$2). Some theorists have claimed that 'knows how to' is ambiguous, for example, between knows how one and is able to (cf. Mackie 1974; Hintikka 1975; Carr 1979, 1981; Katzoff 1984; Rumfitt 2003; Rosefeldt 2004; Hetherington 2006; and Lihoreau 2008). Such ambiguity claims, which are both popular and controversial, constitute substantive linguistic theses that are open to standard linguistic tests for ambiguity (such as those described in Zwicky and Sadock 1975; for a critical application of some of these tests, see Bengson, Moffett, and Wright 2009, 393ff.).

47. An alternative approach that we will not elaborate involves denying (or rephrasing) the relevant anti-anti-intellectualist intuitions, holding that knowing how and powers do not in fact come apart in the relevant cases. Of course, the anti-intellectualist would need to provide fairly compelling reasons for such denial; she would also owe an explanation of the original intuitions, assuming they persist. 
Counterexamples refute proposals, more or less, one at a time.... While they can refute specific instances of a style of theory, counterexamples are not in themselves to the style as a whole. Instead, they are tools for refinement, allowing a better choice of specific instance of that style to be endorsed. (forthcoming, §I)

Thus Hawley $(2003,22)$ has suggested a refinement to the anti-intellectualist style of theory that focuses on a particular counterfactual, namely, if $x$ knows how to $\varphi$ under certain circumstances, then if $x$ tried to $\varphi$ in those circumstances, then $x$ would successfully $\varphi$ (where the circumstances may specify relevant manifestation or enabling conditions; cf. Millikan 2000, ch. 4 and Noë 2005; for critical discussion, see Bengson and Moffett, chapter 7). A slightly more exotic refinement would consist in a nonstandard analysis of a certain type of power, for example, one associated with a conditional possessing distinctive features, for example, one that resists familiar constraints such as centering (and thus differs from the material conditional, the C. I. Lewis strict conditional, and the Lewis/ Stalnaker variably strict counterfactual conditional)..$^{8}$

Counterfactuals and exotic conditionals may not exhaust the anti-intellectualist's options. For example, she might instead investigate the prospects of a "weak" power (perhaps associated with a "weak" noncounterfactual, nonexotic conditional) that together with some additional nonpropositional state or states fully grounds knowledge how. The task would then be to specify the indicated extra state or states. Although it is not clear at this point how such a specification might proceed, the option to pursue it, like the option to pursue an exotic conditional, remains.

\subsection{The Knowledge/Knack Question}

Insofar as a power that accounts for the difference between the Intelligent and the non-Intelligent must allow for the possibility of practical knowledge, as opposed

48. To illustrate, albeit schematically, let $\mathrm{C}$ be such a conditional. Suppose it is true that in all of the cases in which the subject knows how to $\varphi$ while lacking an ability or disposition to $\varphi$, an instance of $\mathrm{C}$ is still true, and that in all of those cases in which the subject does not know how to $\varphi$ while possessing an ability or disposition to $\varphi$, an instance of $C$ is false; indeed, suppose it were shown that $x$ knows how to $\varphi$ if and only if $\mathrm{C}$; then, to the extent that $\mathrm{C}$ is associated with a type of power (e.g., it can be shown to be typically expressed by a modal auxiliary such as 'can', 'could', or 'would'), rather than propositional attitudes, $C$ would enable an anti-intellectualist explanation of the relevant cases and an answer to the delineation question. One of the most pressing questions facing anti-intellectualism is whether any conditional satisfies this description. For relevant discussion of conditionals, see Bonevac, Dever, and Sosa (2006). 
to a mere knack, an anti-intellectualist answer to the delineation question must be developed in tandem with an answer to the knowledge/knack question. How are we to understand the distinction between practical knowledge and a mere knack without appealing to "theoretical" (truth or fact-oriented) cognition? The antiintellectualist might respond that practical knowledge-knowing how, skill, and expertise-is a type of power that involves distinctively practical cognition. This perspective seems to be suggested by Martin Heidegger in Being and Time (which Ryle himself reviewed rather favorably) ${ }^{49}$ :

'Practical' behaviour is not 'atheoretical' in the sense of "sightlessness." The way it differs from theoretical behaviour does not lie simply in the fact that in theoretical behaviour one observes, while in practical behaviour one acts, and that action must employ theoretical cognition if it is not to remain blind; for ... action has its own kind of sight. Theoretical behaviour is just looking, without circumspection. (1926/1962, 99)

The idea is that practical knowledge possesses a proprietary cognitive character (i.e., a cognitive character that is not reducible to the rational, epistemic achievement of truth or fact-oriented states), and it is this proprietary cognitive character that distinguishes it from mere knacks. Of course, a satisfactory development of this style of response to the knowledge/knack question requires an account of the indicated proprietary cognitive character-a type of rational, epistemic achievement that is distinctively practical but at the same time is not merely a matter of successful performance. What is this character, and what makes it a genuinely rational, epistemic achievement?

Anti-intellectualists have several options, besides invoking a primitive (i.e., brute and inexplicable) notion of practical, power-based cognition when attempting to answer this question. First, they may look to Heidegger's notion of circumspection [Umsicht] (and the related notions of readiness-to-hand [Zuhandenheit] and understanding [Verstehen]), which designates "a kind of concern which manipulates things and puts them to use" and in this sense "has its own kind of "knowledge" (Heidegger 1926/1962, 95; see also esp. \$3I).50

49. See Ryle (1929, 370): "I have nothing but admiration for his [Heidegger's] special undertaking and for such of his achievements in it as I can follow, namely the phenomenological analysis of the root workings of the human soul."

50. Interestingly, the early Ryle (1929, 25) seems to have thought that Heidegger did not succeed in eschewing intellectual states, writing that Heidegger's "attempt to derive our knowledge of 'things' from our practical attitudes towards tools breaks down; for to use a tool involves knowledge of what it is, what can be done with it, and what wants doing." It has been suggested 
Second, anti-intellectualists might seek to elaborate Ryle's notion of training (mentioned in \$1.3), which was originally intended to help to distinguish practical knowledge from mere habit. Third, they might draw inspiration from Maurice Merleau-Ponty's (1945/1962, I42ff.) emphasis on a kind of "motor grasping or a motor significance," which he himself regarded as implying that "it is the body which 'understands"' (cf. Dreyfus 1967, 1992, ch. 7, and 2002; Kelly 2002; Carman 2008, IIIff.). Kevin O’Regan and Alva Noë’s (200I, \$3) notion of “knowledge of sensorimotor contingencies," which is said to be related to what Ryle (1949, 230) described as "acquired expectation-propensities" and has affinities with MerleauPonty's “motor grasping," as well as James Gibson's (1977) theory of "affordances" (see also Gregory 1970), may be viewed as a fourth option or a sympathetic elaboration of Ryle's or Merleau-Ponty's basic approach.

Of course, it is not enough simply to introduce a notion and claim that it has a proprietary cognitive character; what is needed is a full, noncircular characterization of a phenomenon that does not implicitly or explicitly appeal to any intellectual states but still plansibly underwrites a type of rational, epistemic achievement beyond the kind of regular, successful performance attainable by mere muddlers and dabblers (in short, a theoretically interesting proprietary cognitive character, statable as such without scare quotes).s. To the extent that one or another of the indicated notions-circumspection, training, motor grasping, knowledge of sensorimotor contingencies, or some combination thereof-can be so characterized, which is of course a non-trivial task, the result may well be an anti-intellectualist-friendly account of the intuitive distinction between practical knowledge and mere knacks.

\subsection{The Complex Practice Question}

Such an account may perhaps inform an anti-intellectualist treatment of the phenomenon of practicing complex intentional actions that we are not yet able or disposed to perform. As we saw, it seems natural to think that practicing such actions requires knowledge how to do what we are seeking to be, and thus are not yet, able or disposed to do. Still, anti-intellectualists might deny this, maintaining that such knowledge how is not in fact required. Instead, they might invoke a minimal power to $\varphi$ (e.g., a mere capacity to $\varphi$ ); such a power, in combination with auxiliary information (e.g., lessons or instructions) regarding what it takes

to us that Heidegger was in fact a proponent of (a nonstandard version of) intellectualism, rather than anti-intellectualism. There is much to be said on behalf of this suggestion.

51. Here we encounter with urgency Mumford's $(1998,25)$ counsel, issued in a slightly different context, that "if... appeal[ing to powers] is to bring benefits, it is essential that it be backed up with a credible account of what [the relevant powers or] dispositions are supposed to be." 
to $\varphi$, could then be said to enable one to practice $\varphi$-ing (given the requisite concentration, awareness, etc.). Perhaps ironically, the anti-intellectualist's explication of the practitioner's grasp of the indicated information might exploit the very propositional attitude(s) to which intellectualists appeal when analyzing or grounding knowledge how, for example, knowledge that $w$ is a way to $\varphi$ - or of some other maxim, imperative, or regulative proposition about what to do in order to $\varphi .^{52}$ The difference between the intellectualist and anti-intellectualist is, of course, that the latter will deny that knowing how itself is or involves any such attitude(s); it simply plays a role in practicing complex intentional actions..$^{33}$

This approach to the complex practice question treats knowledge how as a substantive power, in contrast with the indicated (practice-enabling) minimal power. Such an answer requires an account of the difference between these two types of power that is consistent with anti-intellectualism's answers to the delineation and knowledge/knack questions. It also requires dialectical subtlety. For the appeal to propositional attitudes in anti-intellectualism's explanation of complex practice interacts in potentially hazardous ways with the contention (discussed above) that propositional attitudes are unable to sustain the actionoriented character of knowledge how. Arguably, if the relevant propositional attitudes are action-oriented enough to allow such practice, then they are action-oriented enough to qualify as practical (i.e., they are not merely theoretical); conversely, if the relevant propositional attitudes are not action-oriented enough to qualify as practical (i.e., if they are merely theoretical), then they are not action-oriented enough to allow such practice. In these ways, engaging the complex practice question demands sensitivity to the broader debate between intellectualist and anti-intellectualist views of mind and action.

52. Ryle (1945, I2): "What is the use of such formulæ if the acknowledgement of them is not a condition of knowing how to act...? The answer is simple. They are useful pedagogically, namely, in lessons to those who are still learning how to act. They belong to manuals for novices [and] are banisters for toddlers...."

53. One way to develop this approach involves distinguishing knowledge how to $\varphi$ from knowledge how one $\varphi$-s (or knowledge how $\varphi$-ing is done, knowledge how it is that $\varphi$ is performed, or knowledge of what it takes to $\varphi$; recall note 46) and subsequently holding that only the latter is or involves the indicated propositional attitude. Practicing a complex intentional action could then be said to require, not prior knowledge how to $\varphi$, but rather prior knowledge how one $\varphi$-s (or knowledge how $\varphi$-ing is done, or knowledge of what it takes to $\varphi$, etc.). An entirely different strategy, which we will not evaluate here, allows that practicing a complex intentional action $\varphi$ may require prior knowledge how to act; however, on this alternative, it is denied that this must be knowledge how to $\varphi$. Rather, one knows how to do various other things, and one also knows that doing these other things in such and such order is a way (or what it takes) to $\varphi$; together, this enables one to practice $\varphi$-ing. Cf. Hornsby $(1980,83)$ and Brewer (1999, 243-244). 


\subsection{The Linguistic Question}

While the delineation, knowledge/knack, and complex practice questions force the anti-intellectualist to theorize about the metaphysics of powers, specifying what could make it the case that certain powers are rational, epistemic achievements and serve to make the difference between the Intelligent and the nonIntelligent, answering the linguistics question is, by contrast, a broadly semantic project. Setting aside Intelligence-attributions that do not attribute knowledge how, which might be thought to pose no special problem for anti-intellectualism, an anti-intellectualist response to the linguistics question in the prima facie problematic case of knowledge how (recall \$3.I) may come in two stages: first, deny that the semantics of knowledge-wh constructions, in general, and its relevance to the case of knowledge-how, in particular, are as cut-and-dried as proponents of intellectualism sometimes suggest; second, provide an alternative, anti-intellectualist-friendly semantics that can take the place of the standard, propositional semantics. Let us consider each stage in turn.

As we have seen, intellectualists such as Stanley and Williamson (200I) have claimed that (i) knowledge-how attributions should be treated as embedded questions, on a par with closely related constructions (knowledge where, when, who, etc.), and (ii) the best semantics for embedded questions is propositional in nature. Both claims may be disputed. For example, regarding (i), there is reason to think that a uniform semantic treatment of closely related constructions is not always warranted. To illustrate, consider the following examples offered by Laura Michaelis (chapter II):

I. $x$ learned to $\varphi$.

2. $x$ tried to $\varphi$.

3. $x$ knew to $\varphi$.

4. $x$ understood to $\varphi$.

Despite the overt grammatical similarities, only (3) and (4) can be appropriately paraphrased in terms of normative propositional content (roughly, $x$ knew/ understood that x ought to $\varphi$ ). In a similar way, anti-intellectualists can maintain that 'how-to'-complements are interpreted differently from other whcomplements. This approach might be motivated by the observation that many people seem to be comfortable with an ability-based paraphrase of knowledgehow constructions, whereas an ability-based paraphrase of other knowledge-wh constructions is far less natural.

As for (ii), although it may well be that the standard semantics for embedded questions is propositional in nature, this semantics is not without difficulties of 
its own. For instance, specifying questions by means of sets of propositional answers, as in the standard approach, is potentially problematic. Thus Michaelis (chapter II) argues that, pace the standard view, there is no acceptable existentially quantified proposition that captures the intuitive semantic meaning of sentences such as (5), as suggested by the failure of (6) and (7) to serve as adequate paraphrases:

5. $x$ asked how to $\varphi$.

6. $(\exists w)(x$ asked if $w$ is a way to $\varphi)$.

[In English: There is a way of acting such that $x$ asked if that way of acting is a way to $\varphi$.]

7. $x$ asked if $(\exists w)(w$ is a way to $\varphi)$.

[In English: $x$ asked if there is a way of acting that is a way to $\varphi$.]

In a similar vein, Jonathan Ginzburg (1995a; chapter 9; cf. Ginzburg 1995b, 1996, and Ginzburg and Sag 2000) argues that what counts as an acceptable answer to a given $w$-question seems to be context sensitive in ways that are difficult to square with the standard semantics of embedded questions. The point, of course, is not that such arguments obviously demonstrate once and for all that the standard view is irrelevant or false. Rather, the lesson is simply that the empirical adequacy of the standard view and its applicability to the case of knowing how are far from settled (see also Rumfitt 2003; Collins 2007b, n. 9; Roberts 2009; Stout 2010; Bengson and Moffett chapter 7; Devitt forthcoming-a).

At this point, intellectualists may wish to take refuge in the thought that all of the major historical treatments of embedded questions have been propositional, and that this indicates that any plausible semantics for knowledge-how attributions will be propositional. However, a variety of nonpropositional approaches have found their way into the literature in recent years. These approaches center on, not propositional attitudes per se, but rather de se attitudes (Roberts 2009), objectual attitudes toward ways of acting (Bengson and Moffett chapter 7), and objectual attitudes toward the free variable in a presupposed open sentence (Michaelis chapter II).54 Here we arrive at stage two: providing an anti-intellectualist semantics. To be sure, these approaches may not by themselves deliver complete or exclusive anti-intellectualist semantics; after all, they are consistent with the thesis that the indicated nonpropositional attitudes are eventually grounded in propositional attitudes. Nevertheless, they do locate semantics compatible with

54. This last proposal might be developed within the context of Discourse Representation Theory (Kamp 198I) as involving an attitude toward a discourse referent assumed to be in the common ground. Another option may be Fine's (1985) theory of arbitrary objects. 
anti-intellectualism: in this sense, they yield anti-intellectualist-friendly semantics (in turn, whether the indicated nonpropositional attitudes are grounded in propositional attitudes emerges as a philosophical, nonlinguistic debate). Indeed, each approach takes aim in its own way at the propositionalist heterodoxy on which intellectualist answers to the linguistics question have tended to rely and, thereby, opens up space within which anti-intellectualism can maneuver.

There appear to be two further, radical options available to anti-intellectualism. The first radical option consists in resisting the demand for fealty to ordinary usage of 'knowledge how' and to embark instead on a form of philosophical explication - wherein, roughly, the ordinary notion of knowledge how is replaced with a stipulatively defined notion that is held to preserve the theoretically interesting features of the original notion while shedding its alleged imperfections (cf. Carnap 1947/1956, \$2).55 The second radical option is to accept the standard semantic view of embedded questions, in general, and knowledge how attributions, in particular, as irreducibly propositional but argue that this is consistent with a version of anti-intellectualism according to which the truth-conditions for such attributions are ultimately grounded in corresponding abilities or dispositions to behavior. ${ }^{56}$

The foregoing suggests how intellectualists and anti-intellectualists might answer questions about the delineation of Intelligent action, learning and practicing, the intuitive distinction between practical knowledge and practical knacks, and the semantics of ascriptions of knowledge how and other states of Intelligence. Given the importance of the details, as well as the potentially far-reaching and interdisciplinary character of the surrounding issues, further investigation is, of course, required (several of the chapters in this book contribute to this venture).

\section{Implications and Applications}

The debate between intellectualism and anti-intellectualism intersects with core issues in disparate philosophical areas, including epistemology, ethics, and philos-

55. Presumably, anti-intellectualists must seek a characterization of these alleged imperfections that does not indirectly vindicate intellectualism.

56. This second radical option is roughly the converse of the one taken by Bengson and Moffett (chapter 7), who can be regarded as endorsing a type of radical intellectualism. It is worth emphasizing that this second radical option will not be open to Ryleans or neo-Ryleans aiming to reductively analyze or eliminate internal mental states (e.g., propositional attitudes). Nevertheless, it is surely a strategy that many philosophers sympathetic to Ryle's project will find tempting (cf. White 1982). Note that would-be intellectualists must be careful not to indirectly (and perhaps unwittingly) vindicate the second radical version of anti-intellectualism. 
ophies of action, language, mind, and cognitive science. Focusing on the specific cases of knowing how and skill, this section discusses-or, perhaps more accurately, raises questions about - a few such intersections and gestures at numerous others. (Several are pursued with greater focus and detail in this book's chapters.) The aim is not so much to adjudicate disputes in these areas, but rather to draw attention to the scope and significance of the philosophical theory of Intelligence.

\section{I Epistemology}

Knowing how and skill have been explicitly invoked in a variety of epistemological contexts, beyond debate concerning whether there is a type of knowledge that is fundamentally distinct from knowledge that. Some examples include discussion of skepticism (see, e.g., Gellner 1951, 29-30; Unger 1975, I45-146 and 281-283; Hetherington 2008), the a priori (see, e.g., Toulmin 1949, 176; Gellner 1951, 30ff.; Hetherington 2009), inferential warrant and logical knowledge (see, e.g., Ryle 1945, 6ff.; Powers 1978; Kalderon 200I; Besson 2010; Rumfitt chapter 15), episodic memory and mnemonic justification (see, e.g., Soteriou 2008, 480-484), self-knowledge (see, e.g., Yalowitz 2000), testimony (see, e.g., Hawley forthcoming; cf. Craig 1990, ch. 17), the value of knowledge (see, e.g., Riggs 2002), the problem of the criterion (see, e.g., Hetherington forthcoming), and epistemic injustice (see, e.g., Hawley chapter I2).

Another epistemological application occurs in the increasingly popular field of virtue epistemology, whose emphasis on "epistemic skills" or "competences" and "intellectual virtues" brings it into direct contact with the debate between intellectualism and anti-intellectualism. To illustrate, in $A$ Virtue Epistemology, Ernest Sosa defines propositional knowledge in terms of apt belief, and apt belief in terms of competent, true belief (2007, ch. 2).57 The relevant competence is not wholly un-Intelligent but is a state of intellect and character, for example, knowledge how or skill (Sosa 2003, IOI). Presumably, this is as it should be, if it is true that propositional knowledge-at least when it is "reflective," in Sosa's terminology — cannot be the product of a mere knack (or combination of knacks). The connection to the debate between intellectualism and anti-intellectualism should be plain. Yet, it remains an open question whether a fully developed virtue epistemology is compatible with intellectualism or in fact entails the type of

57. Cf. Sosa (2009, esp. 12-14). In a similar vein, Markie (2006, 130) defends an account of "epistemically appropriate perceptual belief" as the exercise of knowledge how, specifically, "the exercise of knowledge of how to identify objects and their features perceptually." Cf. Reynolds (1991), Zagzebski (1996), Hyman (1999), Bloomfield (2000), Pollard (2003), Battaly (2008), Greco (2009), and Lepock (forthcoming). In their discussions of knowing how and skill (competence, etc.), many of these theorists indicate a commitment to anti-intellectualism. 
anti-intellectualism to which Sosa seems to commit when he explicitly characterizes the relevant competence as

a disposition...that would in appropriately normal conditions ensure (or make highly likely) the success of any relevant performance issued by it. $^{58}(2007,29)$

Now, if intellectualism is true, then such a disposition is un-Intelligent-in which case it seems unable to do the sort of theoretical work required by virtue epistemology. If anti-intellectualism is true, then such a disposition may do the relevant theoretical work; what is then needed to secure the viability of such virtue epistemology is, among other things, an account (perhaps of the sort described in \$3.3) that meets the challenge, hitherto unremarked, to plausibly distinguish such a disposition from an un-Intelligent knack.

\subsection{Ethics}

The debate between intellectualism and anti-intellectualism may interact in analogous ways with philosophical work in virtue ethics. Allegedly following such thinkers as Aristotle and Thomas Aquinas, it is widely believed or assumed by contemporary virtue ethicists that moral virtues are dispositions (or some other type of power). In a recent survey article, Rosalind Hursthouse summarizes:

A virtue such as honesty or generosity is ... a character trait-that is, a [multitrack] disposition which is well entrenched in its possessor. (2009, \$2 emphasis added)

To the extent that moral virtues are or involve states of Intelligence (i.e., they are not wholly un-Intelligent), 59 virtue ethics so understood appears to be committed to a form of anti-intellectualism. As indicated by the challenges discussed in $\$_{3}$, such a commitment is not trivial. At any rate, such commitment may be premature. Arguably, there is room to explore an intellectualist approach to moral

58. However, Sosa elsewhere suggests that knowing how is "a rather special sort of propositional knowledge" (2003, IOI). Notice that if propositional knowledge in general is held to require knowing how or skill, as in Sosa's virtue epistemology, and knowing how or skill in turn requires at least some propositional attitudes, as Sosa here suggests, then regress threatens.

59. Some but not all virtue ethicists characterize virtue as a skill (see, e.g., Annas 1995, 2011; cf. Zagzebski 1996, II.2.4). However, to our knowledge, none denies that the relevant virtues are Intelligent. 
virtues, according to which it is mistaken to think that the core of virtue (and character) can be discerned through a narrow focus on traits and their kin. Rather, on this intellectualist approach, moral virtues are at least partially grounded in intellectual states - which may be said, in turn, to be regularly exercised in appropriate actions. For example, the honest or generous person must have certain propositional attitudes, to which exercises of her honesty or generosity must-in order to qualify as being genuinely honest or generous-be causally related. ${ }^{60}$ Ryle (1940; 1945, 13-14; cf. 1949, Iroff.) himself contemplated, and predictably rejected, a moral view of this sort, but in light of the intellectualist resources discussed in $\$ 2$, such a view may be regarded as now meriting reevaluation.

This is not the only place where intellectualist and anti-intellectualist views make an appearance in core debates in moral theory broadly construed. Questions concerning the role of propositional attitudes (internal acts of engaging regulative propositions, rules, maxims, or principles) in ethical deliberation, practical reasoning, rationality, and moral judgment have animated much contemporary work in metaethics, ethics, and moral psychology (see, e.g., Dewey 1922; Ryle 1940; Smart 1950; Gould 1955; Cross 1959; Bennett 1964; Geach 1966; Kenny 1966; Kupperman 1970, I40ff.; Hintikka 1974b; Mackie 1974; Carr 1981a; Dreyfus and Dreyfus 1982, 1991; Gauthier 1994, e.g. 701-702; Churchland 1996, 143ff. and 2000; Blackburn 1996; Clark 1996, 2000; McDowell 1996; Sayre-McCord 1996; Carr and Steutal 1999; Varela 1999; Audi 2001, ch. 8; Dancy 2004, I42ff.; van Willegenburg 2004; Bartsch and Wright 2005; Railton 2006, 2009; Andreou and Thalos 2007; Wiggins 2009). Participants in the corresponding debates frequently juxtapose propositional attitudes with knowing how or skill, as it is widely believed or assumed that the latter are nonpropositional. One wonders what might happen if this anti-intellectualist supposition is lifted (or at least suspended).

To see what we have in mind, consider first that a similar anti-intellectualist supposition pervades moral epistemology, where the nature and status of moral knowledge remains controversial. In a neglected passage, Ryle himself proposed that

moral knowledge, if the strained phrase is to be used at all, is knowing how to behave in certain sorts of situations in which the problems are neither merely theoretical nor merely technical. $(1949,316)$

6o. The possibility that virtues are partially grounded in intellectual states might suggest a hitherto unexplored connection between virtue ethics and deontology. Intellectualists might also question the popular idea that moral virtues require corresponding abilities or dispositions to act virtuously. Similarly for practical wisdom: see, e.g., Whitcomb (20II), who argues that wisdom does not require a reliable disposition to act wisely. If intellectualism is true, this conclusion is compatible with Ryan's (1996, 1999) suggestion that wisdom is or involves a type of knowledge how. 
Given Ryle's anti-intellectualism, this implies the view that moral knowledge is grounded in abilities or dispositions, rather than propositional attitudes. Annas (1995, 200I, 2011; chapter 4) has argued that this view can and should be resisted: although she defends the thesis that (a significant portion of) our moral knowledge is knowledge how or skill, she maintains that such knowledge or skill cannot be understood without reference to propositional attitudes (see, e.g., 200I, 248). Regardless of whether Annas is correct to recommend intellectualism, surely she is right to implicitly separate the following two types of question:

[QI] Does moral knowledge (virtues, ethical deliberation, practical reasoning, rationality and rational agency, etc.) involve knowing how or skill (Intelligence)?

[Q2] If so, is such knowing how or skill (Intelligence) grounded in abilities or dispositions, rather than propositional attitudes?

While [QI] is, of course, a type of question belonging to moral theory, the project of answering $\left[\mathrm{Q}_{2}\right]$, by contrast, is ultimately a matter of engaging the philosophical theory of Intelligence.

\subsection{Philosophy of Action}

Contemporary work in philosophy of action has fruitfully investigated the metaphysics and the epistemology of intention and intentional action. There is room here to explore intellectualist and anti-intellectualist views about these and kindred phenomena (e.g., volitions, voluntary action, free action, plans, endeavoring). ${ }^{61}$ Are intentions to act grounded in propositional attitudes or, rather, abilities or dispositions to behavior? Are intentional actions produced by the former or, rather, actualizations of the latter? Is knowledge of what one is doing when one acts intentionally—what we might call 'Anscombian practical knowledge' (see Anscombe 1957) - a matter of having propositional attitudes or, rather, some type of power?

Given the connections between intentional action and Intelligent action, it is reasonable to expect discussion of these questions to somehow implicate

6I. See, for example, Ryle's (1949, 64ff.; cf. 1945, 3) discussion of intellectualist theories of volition and voluntary action, which persist still today. For example, Velleman (2000, 195ff.) has recommended what looks to be an intellectualist view of intentional action as behavior preceded by "accepting a proposition in such a way as to make it true," where such acceptance is a type of propositional attitude that he labels 'directive cognition.' Cf. Bratman's (1987) work on plans, Chisholm's (1976, $57 \mathrm{ff}$.; 1988) treatment of undertaking or endeavoring, and Thompson's (2008, 93ff.) remarks on "the intellectual aspect" of action, which he deems "all-important." 
knowledge how and other states of Intelligence. For instance, Jennifer Hornsby (chapter 3 ) suggests that an adequate account of agency must acknowledge that the application of knowledge in processes of acting requires a type of general knowledge-specifically, knowledge how to act-that because of its generality, cannot be exhausted by knowledge of particular propositions applied. And Kieran Setiya $(2008,404)$ has recently argued that, insofar as it is a general principle (which he endorses) that "If $\mathrm{A}$ is doing $\varphi$ intentionally, $\mathrm{A}$ knows how to $\varphi$, or else he is doing it by doing other things that he knows how to do," we are compelled to admit that "Knowledge how belongs at the core of any intentional action." Setiya proceeds to argue that knowledge how also belongs at the core of "dynamic epistemology" and Anscombian practical knowledge:

Knowing how to $\varphi$ is the state or condition that, with knowledge of ability [viz., knowledge that if I intend to $\varphi$, I will be doing so in fact], provides the epistemic warrant for decision. Together, they justify the transition in which one forms the intention and belief that one is doing $\varphi$ or that one is going to do it.... Knowledge how thus plays a role in dynamic epistemology, in our entitlement to form and revise beliefs. This happens continuously in the performance of intentional action... [s]o my knowing how to [act] is constantly implicated in knowledge of what I am doing. (Setiya 2008, 407; cf. Paul 2009 and Setiya 2009)

This attempt to integrate the metaphysics and epistemology of intentional action seems to exploit the simultaneously practical and cognitive-or, recalling Heidegger, the circumspective-character of knowing how, which is not an epistemically inert, arational knack (recall $\$_{3}$ ), but is rather a paradigm example of Intelligence and source of Intelligent action (recall $\$ \$ I-2)$. At the same time, as we have seen, these aspects of knowing how remain to be fully characterized and adequately explained. It is fair to say that further investigation will be needed to determine which of intellectualism or anti-intellectualism is best positioned to offer the requisite illumination vis-à-vis intention and intentional action. ${ }^{62}$

62. Knowing how and skill have both played prominent roles in several other debates in the philosophy of action, including criticism of the so-called causal theory of action (see, e.g., Ruben 2003, I3Iff.; Clarke 2010) and more general issues surrounding the metaphysics and epistemology of agency (see, e.g., Hornsby 1980, ch. 6; Archer 2000; Stanley and Williamson 2001, 442ff.; Gibbons 2001; Kelly 2002; Bengson and Moffett 2007, \$4; Leist 2007; Lekan 2007; Stanley forthcoming-b). Theorists may also explore intellectualist versus anti-intellectualist accounts of the difference between akratic action (weakness of will) and, for example, compulsion or addiction; capacities-based accounts are explored in Holton (1999, 2004), G. Jones (2003), Smith (2003), and Cohen and Handfield (2011). 


\subsection{Philosophy of Language and Linguistics}

Such investigation may also enable a lucid assessment of appeals to knowing how and skill (or "mastery") in the philosophy of language and linguistics. For example, Robert Brandom (1994, I3I) has advanced the inferentialist-cum-pragmatist view that "there is nothing more to conceptual content than its broadly inferential articulation," which is grounded in "a kind of know-how" (87ff.), which in turn "is a matter of practical ability" (23). An anti-intellectualist perspective similarly pervades appeals to knowing how and skill in discussion of nonsense and ineffability (see, e.g., Wittgenstein 1953/1968; Moore 1997; cf. Williamson 1999), Dummettian realism and antirealism (see, e.g., Dummett 1982 and 2006), ${ }^{63}$ imperatives (see, e.g., Ryle 1940; Hare 1972, 3), and rule-following (see, e.g., Ryle 1940, 1945, 1949; Wittgenstein 1953/1968; Kripke 1982; Boghossian 1989; Wright 1989; Brandom 1994, 20ff. and 65ff.; Haugeland 1998, ch. 13; Martin and Heil 1998; Tanney 2000; Kalderon 200I). In each of these cases, one wonders-as in $\$ 4.2$ (recall the distinction between $\left[\mathrm{Q}_{1}\right]$ and $\left[\mathrm{Q}_{2}\right]$ ) - if an anti-intellectualist perspective of the relevant phenomena is compulsory. Viewed another way, it seems reasonable to ask in each case whether the explanandum is an instance of Intelligence: if not, then the appeal to knowing how must be deemed either misleading or superfluous, but if so, then we can begin to consider the further question of whether such Intelligence is best understood in intellectualist or antiintellectualist terms.

Recent debates over the nature and status of linguistic knowledge appear to be premised on the reasonable assumption that such knowledge is or involves a form of Intelligence (see, in particular, Bennett 1964, \$5). Noam Chomsky has argued that the knowledge of language that ordinary speakers possess-in other words, their knowledge how to speak their language-is factual knowledge and cannot be understood in anti-intellectualist terms. ${ }^{64}$ In an obvious allusion to Ryle, Chomsky writes:

Evidently, possession of this knowledge [of language] cannot be identified with ability to speak and understand or with a system of dispositions... or

63. Loux (2003, 642 emphasis added) suggests that Dummett's case for antirealism is linked to the idea that "to understand a statement is to know how to use it properly; and to know that is to have the ability to recognize when the assertion of that statement would be correct."

64. Chomsky (1988, 62-63 emphasis added; cf. 1975, 1980a, 1992): "We may think of the language faculty as a complex and intricate network of some sort associated with a switch box consisting of an array of switches.... When these switches are set, the child has command of a particular language and knows the facts of that language: that a particular expression has a particular meaning, and so on." 
habits. We cannot exorcise the "ghost in the machine" by reducing [such] knowledge to ability, behavior, and dispositions. (1988, IO-II)

Chomsky's opponents ably disagree, of course, and thus the nature and status of knowledge of language remains highly controversial (see, e.g., Wittgenstein 1953/1968; Ware 1973, \$\$4-5; Putnam 1988, 32 and 1996; Dummett 1991, 93ff. and 1993, ch. 3; Devitt 1981, 1984/1997, 2006b, and chapter 14; Schiffer 2003; Hornsby 2005; Stanley 2005; Longworth 2008).

\subsection{Philosophy of Mind, Phenomenology, Cognitive Science, Ethology, and Psychology}

In The Concept of Mind, Ryle himself approached the issue of knowing how and skill through the philosophy of mind (specifically, the mind-body problem), treating them as centerpieces in his attack on a Cartesian dualism of mental and physical that espouses "the dogma of the ghost in the machine." As Although most philosophers today deem Ryle's attack unsuccessful, ${ }^{66}$ it is difficult to deny that it was-and remains-influential, and not simply because its quips and gibes presented anti-Cartesians with a sizable rhetorical advantage.

Such polemical contests aside, knowing how and skill have featured prominently in a variety of other well-known controversies in recent (post-Ryle) philosophy of mind, phenomenology, and cognitive science. These include debates over the nature and possibility of machine or artificial intelligence (see, e.g., MacIntyre 1960; Nowell-Smith 1960; Dreyfus 1967, 1992, 2002; Winograd 1975; Searle 1980; Block 1981; Dreyfus and Dreyfus 1982; Brooks 1991; Haugeland 1998), representationalist theories of mind and knowledge (see, e.g., Dreyfus and Dreyfus 1982; Dreyfus 1992, 2002; Clark and Toribio 1994; Haugeland 1998; Kelly 2002; Clarke 2010, §4; Cummins and Roth forthcoming; Stanley forthcoming-a), Frank Jackson's (1982) Mary argument against physicalism (see, e.g., Nemirow 1980, 1990; Lewis 1983, 1988; Mellor 1993; Raymont 1999; Alter 2001; Stanley and Williamson 2001; Tye 2004; Cath 2009; Glick forthcoming), issues concerning nonconceptual content and concept possession (see, e.g., Noë 2005 and chapter 8; Bengson and Moffett 2007 and chapter 7; Toribio 2007; Kumar 20II; Devitt forthcoming-a; Glick forthcoming), the proper understanding of knowledge of phenomenal character and "what it is like" (see Tye, chapter 13),

65. This connection is revisited by Snowdon (2003, 16) and Hornsby (chapter 3); see also Churchland (1996).

66. Though Rylean approaches have recently seen defense by Mesler (2004) and Stout (2006). 
and the relation between perception and action (see, e.g., Varela, Thompson, and Rosch 1991; Grush 1998; Mandik 1999; O’Regan and Noë 200I; Noë 2004; Schellenberg 2007; Reitveld 2008; Bengson in progress).

It is also common to find knowing how and skill invoked by philosophers, cognitive scientists, ethologists, and psychologists in discussion of the status of animal cognition (see, e.g., MacIntyre 1960, 1999 ch. 3; Nowell-Smith 1960; Bennett 1964; Noë 2005; Wallis 2008; Adams 2009; Bengson, Moffett, and Wright 2009; Devitt forthcoming-a), embodied and situated cognition (see, e.g., Paillard 1960, 1991; Varela et al. 1991; Haugeland 1998; Kelly 2002; Gallagher 2005 , ch. 10), automaticity and flow (see, e.g., Annas chapter 4), tacit representation (see, e.g., Fodor 1968; Dennett 1982; Cummins 1986; Haugeland 1998, ch. 8; Ramsey 2007, ch. 5; cf. Polanyi 1958, 1966), and so-called procedural knowledge or memory (see, e.g., Winograd 1975; Bechtel and Abrahamsen 1991, I06; Pollock and Cruz 1999, I27ff.; Bzdak 2008; Adams 2009; Young 2009; Devitt forthcoming-a; Glick forthcoming). ${ }^{67}$ Such discussions must be approached cautiously, however, as calibration with respect to both topic and terminology awaits confirmation.

To illustrate, consider the apparently prima facie exclusive distinction between procedural knowledge and declarative knowledge. While this distinction is often seductively glossed using the language of 'knowing how' and 'knowing that,' it may be hazardous to simply assume that such a gloss is meant to implicate a genuine equivalence-that whatever the notion of declarative knowledge designates is equivalent to knowledge that (or a subset of propositional attitudes) and that whatever the notion of procedural knowledge designates is equivalent to knowledge how. In this vein, cognitive scientists Neil Stillings, Steven Weisler, Christopher Chase, Mark Feinstein, Jay Garfield, and Edwina Rissland warn:

67. This list does not purport to be exhaustive. For example, knowing how and skill are also discussed in empirical literature on child development, language acquisition, implicit learning, motor learning and "double disassociation," expert systems, and the popular theory of multiple intelligences, among other areas. See Kaufman, Kaufman, and Plucker (forthcoming) for a review of contemporary psychological theories of intelligence.

There are still further areas where the debate between intellectualism and anti-intellectualism may have implications: for example, philosophy of education (see, e.g., Ryle 1945, 15-16; Beck 1968; Carr 1981b, 1984; Schön 1983; Cunliffe 2005; Winch 2009), aesthetics and the theories of art and creativity (see, e.g., Carr 1984, 1987, 1999; Gaut 2009), the study of religion (see, e.g., Ryle 1949, 23; Griffiths 2003, $39 \mathrm{ff}$.; Moore 2003), discussion of the status of Dasein and the question of Being (arising from Heidegger 1926/1962), and non-Western thought and comparative philosophy (see, e.g., Raphals 1992; Ivanhoe 1993; Lai 2007; Stalnaker 2010). 


\begin{abstract}
Traditional [Ryle-inspired] epistemology distinguishes between knowing how and knowing that.... [T] his distinction is not the same as the one psychologists draw between procedural and declarative knowledge.... Much of our knowledge-that is probably encoded declaratively, since much of it is mobilized in controlled processes. Similarly, the kinds of automated, production-style skills we have are typically demonstrated in situations where 'know-how' is the most apt characterization of the knowledge in question.... However, these distinctions do not coincide exactly. ${ }^{68}(1995,369)$
\end{abstract}

Similar warnings may be applied elsewhere, for example, to the notions of automaticity and tacit representation. To borrow a metaphor due to Wilfred Sellars (1962), it is fair to say that our understanding of both the manifest image and the scientific image would benefit from further investigation of the connections, if any, between the everyday notions of knowing how and skill, which are paradigm instances of states of Intelligence, and the technical or semitechnical notions of procedural knowledge, automaticity, and tacit representation (for example) figuring prominently in contemporary cognitive science, ethology, and psychology. ${ }^{69}$

68. Devitt (forthcoming-a, $\$_{3}$ ) characterizes the distinction thus: "declarative knowledge is explicit, accessible to consciousness, and conceptual, [whereas] procedural knowledge is implicit, inaccessible to consciousness, and subconceptual." This characterization nicely highlights one difficulty that arises from assuming the equivalence thesis: it is not obvious that knowledge that and knowledge how possess the indicated features (for example, even Ryle allowed that knowledge that may be implicit; recall note 9). A second difficulty is that a variety of non-Intelligent entities such as calculators, visual systems, and dishwashers represent rules or procedures - the standard characterization of procedural knowledge-whereas they do not possess knowledge how. This is related to a third difficulty: given that such entities possess procedural knowledge, it is far from clear that so-called procedural knowledge is in fact a form of knowledge (cf. Ramsey 2007, 169-173). A fourth difficulty is that the representation of rules or procedures is not obviously nonpropositional; consequently, it may not be of any use to anti-intellectualists wishing to defend Ryle's claim that there is an exclusive (or fundamental) distinction between knowledge how and knowledge that. Fifth, there is reason to think that Ryle himself would have been very unhappy with internal mental representations of rules or procedures (cf. Dennett 1982, 214 and Tanney 2009), regardless of what label such representations are given.

69. In this connection, consider MacIntyre's (1960,90) interesting remarks on nonstandard uses of Intelligence-epithets: "Provided the psychologist is clear and consistent in his usage, is it not open to him to use 'intelligence' as he likes? This ... ignores the point of the psychologist's enterprise. For the psychologist claims to be able to provide us with predictive techniques for assessing intelligence in our sense of the word, or at least in a sense akin to our sense. It is open to the psychologist to invent any technical terms that he can find a need for; there is no a priori reason for giving fewer rights to ' $G$ ' than to 'meson' or to 'chromosome.' But like 'meson' and 'chromosome' in the end ' $G$ ' has to be made intelligible in terms which start from the nontechnical.” Cf. Thompson (2008, io). 


\subsection{The Substantive Character of Ryle's Fault Line}

To some, these observations will serve to uncover the possibility that the "theoretically interesting" states designated by the aforementioned technical or semitechnical notions (e.g., so-called 'procedural knowledge') lie elsewhere than knowing how and skill. Might this possibility render the philosophical debate between intellectualism and anti-intellectualism nonsubstantive, or merely terminological, and therefore uninteresting? No.

To see this, consider the following scenario. It may turn out that what is needed for a given theory (e.g., an account of what Jackson's Mary learns upon leaving her black-and-white room, or a so-called enactive theory of vision $)^{70}$ to succeed may just be the existence of at least one "anti-intellectual" state; that is, what matters is simply that there is some state or other that is grounded in powers, rather than propositional attitudes, and that plays the relevant theoretical role. An anti-intellectualist who endorses the indicated theory might then allow that everyday knowing how or skill is not such a state, but add-perhaps in a deflationary tone of voice-that this merely implies that theorizing about everyday knowledge how or skill is ultimately less important than studying the relevant type of power. One problem with this addition (and the accompanying tone) is that while it would be a triviality that the state in question is grounded in powers rather than propositional attitudes, it would remain a substantive question whether states of Intelligence and Intelligent action are grounded in powers rather than propositional attitudes. Viewed another way, the problem is that it would still be a substantive question whether the "anti-intellectual" state in question was in fact an instance of Intelligence and a Producer of Intelligence: a state of intellect and character, like knowing how and skill. Perhaps it is not. Nor, perhaps, are all of the states designated by the technical or semitechnical notions discussed at the end of the previous subsection $(\$ 4.5)$. This is a possibility that cannot be ruled out by mere stipulation. Nor, arguably, is it settled by the relevant empirical science alone. After all, while such states might play a crucial theoretical role in extant explanations of behavior (perhaps even agentive behavior), they might not play such a role in a philosophically adequate explanation of Intelligent action. On the other hand, they might. The substantive character of these issues should make clear why an appreciation of and sensitivity to distinctions, or potential distinctions, like those sketched at the end of the previous subsection, does not induce trivialization.

These considerations can be used to highlight the broader significance of the philosophical theory of Intelligence, as described in \$I.I and \$2.I. Insofar as the

70. See the citations in $\$ 4.5$. 
indicated theoretical role requires a state that is an instance of Intelligence and a Producer of Intelligence, the approach taken by our imaginary anti-intellectualist will not be available, for intellectualism entails that all of the candidate statesall instances of Intelligence and Producers of Intelligence, and thus all the states that could play the requisite theoretical role - are grounded in propositional attitudes. So the proposed shift simply cannot be made. The same point applies mutatis mutandis to intellectualists who attempt an analogous shift in the other direction. In general, any such shift emerges as untenable once we attend to the fault line uncovered by Ryle's discussion and consequently make plain the "bigger picture". To the extent that this fault line implies a division between intellectualist and anti-intellectualist conceptions of mind and action of the sort described in \$2.I, sustained attention to the aforementioned arguments and issues centering on knowing how, skill, and other states of Intelligence promises to bear substantial-and substantive- theoretical fruit. ${ }^{71}$

7I. Thanks to Bruin Christensen, Sue Deuber, Stephen Hetherington, Jeff Lockwood, Leon Leontyev, John Maier, Matthieu Marion, Aidan McGlynn, Elliot Paul, Raul Saucedo, Susanna Schellenberg, and Jennifer Wright for helpful comments and discussion. 
